\title{
Can Currency-Based Risk Factors Help Forecast Exchange Rates?
}

\author{
Shamim Ahmed* \\ Xiaoquan $\mathrm{Liu}^{\dagger}$ \\ Giorgio Valente
}

December 21, 2014

\begin{abstract}
This paper examines time-series predictability of bilateral exchange rates from linear factor models that utilize unconditional and conditional expectations of three currency-based risk factors. Exploiting a comprehensive set of statistical criteria, we find that all versions of the linear factor models largely fail to outperform the benchmark of random walk with drift model in the out-of-sample forecasting of monthly exchange rate returns. This holds true for individual currencies and currency portfolios formed on forward discounts. We also show that the information embedded in the currency-based risk factors does not generate systematic economic value to investors.
\end{abstract}

JEL Classification: F31, F37, G11, and G17.

Keywords: Exchange Rates, Out-of-Sample Predictability, Economic Value, Time Series, and Econometric Models.

\footnotetext{
*Nottingham University Business School, University of Nottingham, Nottingham, NG8 1BB, United Kingdom. E-mail: shamim.ahmed@nottingham.ac.uk.

${ }^{\dagger}$ Corresponding author. Nottingham University Business School China, University of Nottingham Ningbo, Ningbo 315100, China. E-mail: xiaoquan.liu@nottingham.edu.cn. Phone: +86 574 88180207. Fax: +86 574 88180125 .

${ }^{\ddagger}$ College of Business, City University of Hong Kong, Kowloon, Hong Kong. E-mail: g.valente@cityu.edu.hk.
} 


\section{Introduction}

A voluminous literature, dating back to Meese and Rogoff (1983a,b), suggests that exchange rates are very difficult to predict using traditional economic fundamental-based models, especially at short horizons. ${ }^{1}$ It has become a widely accepted view in international finance that individual exchange rates closely follow random walks (Engel and West (2005), Della Corte and Tiakas (2012), and Verdelhan (2013)).

In search of shedding new light on this stylized fact, the predictive ability of factor models has been explored in the recent literature. Engel et al. (2015) construct common factors from a panel of 17 currencies using the principal component decomposition. The idiosyncratic deviations from the factors are found to contain information for forecasting purposes. Greenaway-McGrevy et al. (2014) further analyze the information in three key currency pairs, i.e., euro, Swiss franc, and Japanese yen against the US dollar (USD), and implement multilateral models of exchange rate variation. The authors show that the new multilateral models are able to significantly outperform the conventional bilateral models using the purchasing power parity (PPP) as a benchmark. Also related, Berg and Mark (2014) explore the third-country effect to deal with a potential omitted variables problem in exchange rate forecasting.

The factor model approach has also been adopted with some degree of success to study currency excess returns in a conventional asset pricing setting. Specifically, Lustig et al. (2011) follow a portfolio approach consistent with the Arbitrage Pricing Theory (henceforth APT) of Ross (1976) and construct two currency-based risk factors, namely, the dollar risk (DOL) and the carry risk (HML). The former is the monthly average excess return between the domestic (US) and all other foreign currencies, while the latter is the monthly excess return differential between a basket of high interest rate currencies and that of low interest rate currencies. In-sample results suggest that the DOL and HML factors account for most of the time-series variation in excess returns of currency portfolios sorted by forward discounts. The two factors explain the time-series movements in exchange rate returns at the portfolio-level as well. However, only the HML factor accounts for the cross-sectional heterogeneity in currency excess returns. Building on these findings, and consistent with the prediction of the Intertemporal Capital Asset Pricing Model (ICAPM), Menkhoff et al. (2012) show empirically that innovations in the global foreign

\footnotetext{
${ }^{1}$ Mark (1995) and Chinn and Meese (1995) provide evidence that exchange rates are predictable at long horizons. More recently, Evans and Lyons (2002, 2005) resort to a microstructure approach and show that private order flow information helps forecast exchange rates at short horizons. Furthermore, Molodtsova and Papell (2009) argue that exchange rates are predictable at short horizons with Taylor rule fundamentals. Note that Taylor (1993) posits a policy rule that closely approximates the Federal Reserve policy on adjusting the short-run nominal interest rate. The rule sets policy rate based on current inflation rate, inflation gap, output gap, and equilibrium real interest rate. A non-exhaustive list of studies investigating the predictability of exchange rates from different perspectives includes Diebold and Nason (1990), Engel and Hamilton (1990), Cheung et al. (2005), and Rossi (2013).
} 
exchange (FX) volatility, VOL, also explain the time-series and cross-sectional variation in carry trade portfolio excess returns.

While these studies report success in the in-sample time-series and cross-sectional modeling, policy makers and practitioners including FX fund managers are keenly interested in the accurate forecasting of future exchange rates, as a model's in-sample predictive performance tends to correlate poorly with its ability to generate satisfactory out-of-sample forecasts (Inoue and Kilian $(2004,2006)$ ). There is ample evidence that unconditional and conditional versions of multifactor asset pricing models are often used to compute expectations of returns in practice, especially in the context of equity markets (see Simin (2008) and the references therein). Hence, a natural question arises: Do currency-based risk factors contain information that adds to the out-of-sample predictability of exchange rates? Motivated by this question, in this paper we investigate whether linear factor models with unconditional and conditional expectations of currency-based risk factors provide accurate forecasts of future bilateral exchange rate returns in the time-series domain. ${ }^{2}$ In particular, the primary goal of this paper is examine whether the asset pricing models proposed in the recent FX rate literature are able to provide accurate expectations of future exchange rate returns. We examine this issue for individual currencies and currency portfolios sorted by forward discounts.

A second question that we are interested in is the economic value of the forecasts. It is not always the case that statistical significance would directly imply economic value from an investor's perspective (Della Corte et al. (2009) and Thornton and Valente (2012)). Hence, we extend the empirical analysis to determining the economic value of a dynamic mean-variance efficient asset allocation strategy that exploits the predictability in exchange rate returns. To do this, we quantify portfolio payoffs to an investor as he switches currency forecasts from the benchmark model to those from the competing linear factor models assuming a reasonable level of risk aversion.

We contribute to the existing literature in several important ways. First, differently from the existing literature on exchange rate forecasting with macroeconomic fundamentals, we focus on a set of very different potential predictors which has been found significant in explaining the time-variation of exchange rate returns and excess returns in-sample. Second, in contrast to the asset pricing literature that is mostly concerned with explaining what generates the returns

\footnotetext{
${ }^{2}$ In our study, we focus on the predictability of nominal exchange rates instead of the predictability of currency excess returns (or deviations from the uncovered interest rate parity) as in the asset pricing literature for two main reasons. First, we aim at contributing to the literature on exchange rate forecasting in the spirit of Meese and Rogoff (1983a) study. Second, and most importantly, the definition of currency excess returns shows that the predictability of exchange rates is tantamount to the predictability of currency returns as interest rate differentials are predetermined variables at the time the forecasts are made. A similar choice is often made in the context of equity markets where the predictability of equity returns (not excess returns) is usually investigated (see, among others, Van Binsbergen and Koijen (2010), and the references therein).
} 
to risky assets, especially with reference to the existence and the dynamics of risk premia, we focus on the assessment of factor models based on forecast errors rather than pricing errors. This differentiation allows us to achieve the main goal of the paper, that is assessing whether asset pricing models proposed in the recent literature are able to provide accurate expectations of future exchange rate returns, at the same time circumventing some well-known issues in the asset pricing literature (for example, among others, useless-factor biases, errors-in-variable problems, data-snooping biases, use of weak instruments, etc.). ${ }^{3}$ Third, we focus on both dimensions of the assessment of out-of-sample predictability: statistical and economic. In fact, while the existing literature on exchange rate predictability mostly focuses on the statistical evidence of it, very few studies have investigated the economic value of predictability accruing to investors who exploit such predictability in asset allocation strategies. One common finding recorded in this recent literature is that it is important to provide evidence of both to show whether any statistical evidence of predictability is also associated with a genuine economic value (McCracken and Valente (2014)).

The findings of our empirical investigation are as follows. First, we find that the random walk with drift benchmark remains the best-performing model in the out-of-sample horse race. Although the risk factors have been shown to be able to explain the in-sample time-series variation of exchange rate returns and excess returns, they largely fail to outperform the baseline random walk with drift model in the out-of-sample tests. The evidence of success associated with forecasts from factor models is feeble regardless of factor expectations, estimation methods, comparison with alternative benchmarks (such as PPP), and forecast horizons or whether we focus on individual currencies or currency portfolios sorted by forward discounts. Second, our assessment of the economic value associated with a dynamic asset allocation strategy that employs the out-of-sample forecasts confirms and reinforces our preceding finding. In fact, the assessment of the out-of-sample economic value shows that the linear factor models do not outperform the random walk with drift benchmark in economic terms. This implies that there is no exploitable economic value to a risk averse investor who switches from forecasts based on the random walk with drift benchmark to those from any competing linear factor models when dynamically rebalances his portfolio. The observation holds irrespective of sample country compositions or factor expectations although the degree of underperformance varies across model specifications. This result provides valuable implications for practitioners in the FX markets who require accurate forecasts of future exchange rate returns to design active

\footnotetext{
${ }^{3}$ The methodology adopted in this paper also allows us to abstract from the debate on the efficiency differences between the estimates of the risk premia using the traditional beta and the stochastic discount factor frameworks (Jagannathan and Wang (1996), Kan and Zhou (1999), Cochrane (2001), and Farnsworth et al. (2002)).
} 
currency management strategies.

Clearly, all of these results support the longstanding view in the exchange rate literature that it is difficult to forecast nominal exchange rates out of sample. Our empirical findings also echo those in the equity market examined in Simin (2008), who reports weak predictive performance of unconditional and conditional asset pricing models for portfolio and individual firm returns. The author provides evidence that the CAPM of Sharpe (1964) and Lintner (1965) and the three-factor model of Fama and French (1993) fail to produce expectations significantly better than the historical average of the market return.

The remainder of the paper proceeds as follows. The next section outlines the empirical linear factor models for exchange rate returns and the construction of the currency-based risk factors and their expectations. Section 3 describes the statistical methods used to evaluate the predictive performance over time and a general framework to quantify the economic value of a dynamic asset allocation strategy that employs one-step ahead expectations of exchange rate returns. In Section 4, we summarize the data and the empirical results of out-of-sample exercises, and discuss the findings from robustness tests. Finally, Section 5 concludes. We provide additional results in the Appendix.

\section{Models and Statistical Evaluation}

In this section, we first outline a set of linear factor models for exchange rate returns in the time-series domain. We then discuss the construction of the risk factors and their expectations used in the subsequent empirical investigation.

\subsection{Models Based on Risk Factors}

The starting point of our analysis is a general representation of a linear factor asset pricing model in the spirit of the Ross (1976) APT for each currency return:

$$
\begin{aligned}
E\left\{\Delta s_{t}^{k} \mid z_{t-1}^{k}\right\} & =\alpha_{t}^{k}+\beta_{t}^{k \prime} E\left\{F_{t} \mid z_{t-1}^{k}\right\} \\
\alpha_{t}^{k} & =a_{0}^{k}+a_{1}^{k} z_{t-1}^{k} \\
\beta_{t}^{k} & =b_{0}^{k}+b_{1}^{k} z_{t-1}^{k}
\end{aligned}
$$

where $\Delta s_{t}^{k}=s_{t}^{k}-s_{t-1}^{k}, z_{t}^{k}=s_{t}^{k}-f_{t}^{k}, s_{t}^{k}$, and $f_{t}^{k}$ stand for exchange rate return, forward discount, and spot and one-month forward exchange rates in logs at the end of month $t$ for a 
given currency $k$, respectively. ${ }^{4,5} F$ denotes a $3 \times 1$ vector of currency-based risk factors, which comprises DOL, HML, and VOL, and the choice of the instrument $z_{t-1}^{k}$ follows Lustig et al. (2011) and Verdelhan (2013). ${ }^{6}$ This model is able to encompass the frameworks proposed in Ross (1976) and Menkhoff et al. (2012) and has its theoretical foundation in no-arbitrage models for interest rates and exchange rates (Backus et al. (2001) and Brennan and Xia (2006)) and the ICAPM (Campbell $(1993,1996))$, respectively.

We first set our benchmark consistent with a random walk with drift:

$$
\Delta s_{t}^{k}=a_{0}^{k}+e_{t}^{k}
$$

We then consider variations of the general form in equation (1) as follows:

$\underline{\text { Unconditional Factor Models }}$

$$
\begin{gathered}
\Delta s_{t}^{k}=a_{0}^{k}+b_{0,1}^{k} D O L_{t}+e_{t}^{k}, \\
\Delta s_{t}^{k}=a_{0}^{k}+b_{0,1}^{k} D O L_{t}+b_{0,2}^{k} H M L_{t}+e_{t}^{k}, \\
\Delta s_{t}^{k}=a_{0}^{k}+b_{0,1}^{k} D O L_{t}+b_{0,3}^{k} \text { VOL }_{t}+e_{t}^{k},
\end{gathered}
$$

\section{$\underline{\text { Conditional Factor Models }}$}

$$
\begin{gathered}
\Delta s_{t}^{k}=a_{0}^{k}+b_{0,1}^{k} D O L_{t}+b_{1,1}^{k} z_{t-1}^{k} D O L_{t}+e_{t}^{k}, \\
\Delta s_{t}^{k}=a_{0}^{k}+b_{0,1}^{k} D O L_{t}+b_{1,1}^{k} z_{t-1}^{k} D O L_{t}+b_{0,2}^{k} H M L_{t}+b_{1,2}^{k} z_{t-1}^{k} H M L_{t}+e_{t}^{k} \\
\Delta s_{t}^{k}=a_{0}^{k}+b_{0,1}^{k} D O L_{t}+b_{1,1}^{k} z_{t-1}^{k} D O L_{t}+b_{0,3}^{k} V O L_{t}+b_{1,3}^{k} z_{t-1}^{k} V O L_{t}+e_{t}^{k}, \\
\Delta s_{t}^{k}=a_{0}^{k}+a_{1}^{k} z_{t-1}^{k}+b_{0,1}^{k} D O L_{t}+e_{t}^{k}, \\
\Delta s_{t}^{k}=a_{0}^{k}+a_{1}^{k} z_{t-1}^{k}+b_{0,1}^{k} D O L_{t}+b_{0,2}^{k} H M L_{t}+e_{t}^{k}, \\
\Delta s_{t}^{k}=a_{0}^{k}+a_{1}^{k} z_{t-1}^{k}+b_{0,1}^{k} D O L_{t}+b_{0,3}^{k} V O L_{t}+e_{t}^{k}, \\
\Delta s_{t}^{k}=a_{0}^{k}+a_{1}^{k} z_{t-1}^{k}+b_{0,1}^{k} D O L_{t}+b_{1,1}^{k} z_{t-1}^{k} D O L_{t}+e_{t}^{k}, \\
\Delta s_{t}^{k}=a_{0}^{k}+a_{1}^{k} z_{t-1}^{k}+b_{0,1}^{k} D O L_{t}+b_{1,1}^{k} z_{t-1}^{k} D O L_{t}+b_{0,2}^{k} H M L_{t}+b_{1,2}^{k} z_{t-1}^{k} H M L_{t}+e_{t}^{k},
\end{gathered}
$$

\footnotetext{
${ }^{4}$ Throughout the paper, the exchange rates are defined as the domestic currency price of a unit of foreign currency.

${ }^{5}$ Akram et al. (2008) show that covered interest rate parity (CIP) holds approximately at daily and lower frequencies in FX markets. This implies the empirical validity: $f_{t}-s_{t} \approx i_{t}-i_{t}^{*}$, where $i_{t}$ and $i_{t}^{*}$ denote one-month domestic and foreign risk-free nominal interest rates, respectively.

${ }^{6}$ We exclude the global FX skewness, the coskewness measure of Harvey and Siddique (2000), and proxies for market liquidity such as the global FX bid-ask spread, the TED spread, and the Pastor and Stambaugh (2003) liquidity measure for the US stock market. This is because Menkhoff et al. (2012) show empirically that global FX volatility dominates these factors in explaining time-varying risk premia for a large cross-section of currencies.
} 


$$
\begin{aligned}
\Delta s_{t}^{k}= & a_{0}^{k}+a_{1}^{k} z_{t-1}^{k}+b_{0,1}^{k} D O L_{t}+b_{1,1}^{k} z_{t-1}^{k} D O L_{t}+b_{0,3}^{k} V O L_{t}+b_{1,3}^{k} z_{t-1}^{k} V O L_{t}+e_{t}^{k}, \\
\Delta s_{t}^{k} & =a_{0}^{k}+a_{1}^{k} z_{t-1}^{k}+b_{0,1}^{k} D O L_{t}+b_{1,1}^{k} z_{t-1}^{k} D O L_{t}+b_{0,2}^{k} H M L_{t}+b_{1,2}^{k} z_{t-1}^{k} H M L_{t} \\
& +b_{0,3}^{k} \text { VOL }_{t}+b_{1,3}^{k} z_{t-1}^{k} V O L_{t}+e_{t}^{k} .
\end{aligned}
$$

It is important to emphasize that contemporaneous regressions of the kind specified above are not uncommon in the forecasting literature. Such models are used when one is interested in the evaluation of the predictive ability of a model given a path for some unmodeled set of variables (see West (1996), Simin (2008), Ferraro et al. (2012), and the references therein).

\subsection{Construction of Risk Factors and their Expectations}

We construct the DOL and HML factors following the methodology proposed in Lustig et al. (2011). At the end of month $t-1$, all available currencies are assigned to five portfolios based on their forward discounts $s-f$ observed at the end of month $t-1$. Currencies are ranked in ascending order with respect to their forward discounts. The first portfolio comprises $20 \%$ of currencies with the smallest forward discounts (or lowest interest rates), while the last portfolio comprises $20 \%$ of currencies with the largest forward discounts (or highest interest rates). The monthly excess return to an investor buying a foreign currency $k$ in the forward exchange market and selling back the currency in the spot market a month after is computed as $r x_{t}^{k}=s_{t}^{k}-f_{t-1}^{k}$. In this way, we estimate the excess return of a currency portfolio constructed at the end of month $t-1$, but realized at the end of month $t$ as the equally weighted average of excess returns for the constituent currencies.

This allows us to construct: (1) DOL as the equally weighted average excess return of the five currency portfolios; and (2) HML as the excess return differential between the last and first portfolios, i.e., the high-minus-low carry trade portfolio. The DOL factor is essentially the excess return from borrowing in USD and investing in a broad basket of foreign currencies. Moreover, DOL has the interpretation of being the aggregate FX market excess return similar to the excess return on the market portfolio in factor models like Fama and French (1993) for stock markets. In contrast, the HML factor is the payoff from a dollar neutral strategy, which involves borrowing currencies in the lowest interest rate quintile and investing currencies in the highest interest rate quintile. We repeat this procedure at the end of every month over the sample period to obtain the time-series of the risk factors.

Following Menkhoff et al. (2012), we construct a time-series measure to proxy for global FX volatility on a daily basis. In particular, we estimate the average of absolute log returns for 
all currencies $k=1,2, \ldots, K$ available on each trading day $\tau$ in the sample spot FX market. The daily mean values are then averaged over the number of trading days in each month. This simple proxy measure is given by

$$
\sigma_{t}^{F X}=\frac{1}{T_{t}} \sum_{\tau \in T_{t}}\left[\sum_{k \in K_{\tau}}\left(\frac{\left|s_{\tau}^{k}-s_{\tau-1}^{k}\right|}{K_{\tau}}\right)\right],
$$

where $T_{t}$ denotes the total number of trading days in month $t$. Finally, we obtain the global FX volatility innovations as the first differences of the monthly volatility series $\sigma_{t}^{F X}$, i.e., $V O L_{t}=\Delta \sigma_{t}^{F X}$. We obtain the unconditional expectations of each risk factor at the end of month $t$ by computing the time-series averages of the corresponding factor from the rolling and recursive windows ending at month $t$ as the forecasts for month $t+1$. The conditional expectations of the same risk factors are computed using predictive regressions. For the DOL factor, we first run both rolling and recursive regressions of the form: $D O L_{t}=\phi_{0,1}^{k}+\phi_{1,1}^{k} z_{t-1}^{k}+\epsilon_{t}^{k}$ for a given currency $k .^{7}$ Next, we use the linear projections $\hat{\phi}_{0,1}^{k}+\widehat{\phi}_{1,1}^{k} z_{t}^{k}$ as the corresponding conditional expectations $E_{t, k}\left\{D O L_{t+1} \mid z_{t}^{k}\right\}$. We follow the same procedure to form the conditional expectations of the HML and VOL factors at the end of month $t .^{8}$

We obtain one-month ahead forecasts for exchange rate returns both at the currency- and portfolio-level using the random walk with drift benchmark and each linear factor model specification given in Section 2.1. At the portfolio-level, $\overline{\Delta s}_{t}^{j}$ and $\bar{z}_{t-1}^{j}$ replace $\Delta s_{t}^{k}$ and $z_{t-1}^{k}$, respectively. We construct $\overline{\Delta s}_{t}^{j}$ corresponding to forward discount-sorted portfolio $j=1,2, \ldots, 5$ as the equally weighted average of $\Delta s_{t}^{k}$ for the constituent currencies. In particular, $\overline{\Delta s}_{t}^{j}=$ $\frac{1}{K_{t-1}^{j}} \sum_{k=1}^{K_{t-1}^{j}} \Delta s_{t}^{k}$, where $K_{t-1}^{j}$ denotes the number of currencies available in portfolio $j$ at the end of month $t-1$. Likewise, $\bar{z}_{t-1}^{j}$ for portfolio $j$ is the equally weighted average of $z_{t-1}^{k}$ for the currencies comprising the portfolio, i.e., $\bar{z}_{t-1}^{j}=\frac{1}{K_{t-1}^{j}} \sum_{k=1}^{K_{t-1}^{j}} z_{t-1}^{k}$. The benchmark for the step-ahead prediction comparison is also the random walk with drift model for the portfolio exchange rate change. Besides, $\bar{z}^{j}$ and $j$ replace $z^{k}$ and $k$, respectively, in the predictive regressions forming the conditional expectations of the risk factors.

We conduct the forecasting exercises using: (1) rolling (least squares) regressions with a constant eight-year window; and (2) recursive regressions with an initial eight-year window that successively increases every time a new observation is added to the estimation window. ${ }^{9}$

\footnotetext{
${ }^{7}$ For ease of exposition, we use the same notation for the rolling and recursive regressions.

${ }^{8}$ It is worthwhile noting that our framework is consistent with Simin (2008), who adopts a similar methodology to assess the predictive power of the market returns (and the two Fama-French portfolio factors) for the timeseries of asset returns. However, even when a nontradable factor is used as a predictor (i.e., global FX volatility), our procedure generates conditional and unconditional forecasts of the first difference of the factor that, in small samples, are empirically dependent on the length of the sample period used in the estimation and the serial correlation of the time-series to be forecasted.

${ }^{9}$ Pesaran and Timmermann (2005) suggest that although a shorter estimation window size allows a parameter
} 
The expectations of exchange rate returns from linear factor models are formed based on both unconditional and conditional expectations of DOL, HML, and VOL factors. To do this, at the end of each forecast origin month $t$, we first obtain the in-sample estimates of the parameters of the models using the risk factor(s) ending at month $t$ (including $z_{t-1}^{k}$ as appropriate). Then we substitute the unconditional and conditional expectations of the factor(s) for month $t+1$ along with the estimated parameters (including $z_{t}^{k}$ as appropriate) into equations (3)-(15) to obtain the forecasts of exchange rate returns for month $t+1$ in the out of sample.

\section{Forecasting Assessment}

\subsection{Statistical Measures of Forecast Accuracy}

To assess the predictive ability of the linear factor models with currency-based risk factors, we exploit two statistical evaluation criteria. The first out-of-sample statistical metric of accuracy is the Diebold and Mariano (1995) and West (1996) mean squared forecast error (MSFE) $t$-statistic, which tests whether a competing model $(i)(i=3,4, \ldots, 15)$ outperforms the random walk with drift benchmark (equation (2)) by producing more accurate forecasts. The test statistic is given by

$$
\operatorname{MSFE}_{i}^{k}-t=\frac{1}{P_{k}^{0.5} \hat{\Omega}_{i, k}^{0.5}} \sum_{t=M+1}^{T_{k}-1} \Delta L_{i, M, t+1}^{k},
$$

where $T_{k}$ is the total number of observations available in the sample, $M$ is the number of observations in the estimation window, $P_{k}\left(=T_{k}-1-M\right)$ is the number of one-month ahead forecasts, $\Delta L_{i, M, t+1}^{k}$ is the difference between the squared forecast error loss functions of the benchmark and competing models, and $\hat{\Omega}_{i, k}$ is the consistent estimate of the asymptotic variance of $\frac{1}{P_{k}^{0.5}} \sum_{t=M+1}^{T_{k}-1} \Delta L_{i, M, t+1}^{k}$. The null hypothesis is specified as

$$
\mathrm{H}_{0}: E\left[\Delta L_{i, M, t+1}^{k}\right]=0
$$

Since a competing linear factor model nests the benchmark random walk with drift model, the alternative hypothesis is one-sided (to the right) rather than two-sided. Rejection of the null hypothesis implies that the competing model has a smaller MSFE than the benchmark. We regress $\Delta L_{i, M, t+1}^{k}$ on a constant and obtain the Diebold and Mariano (1995) and West (1996)

to adapt more quickly to structural breaks, the parameter is less efficiently estimated. On the other hand, a large estimation window size provides a more efficient parameter estimate but leads to a lower power due to fewer observations available for forecast evaluation. Considering this trade-off, the choice of a eight-year rolling window size is reasonable. In addition, to address potential data-snooping biases, we also consider a five-year window and find the out-of-sample results remain qualitatively the same to those reported in Section 4 . These results are available from the authors upon request. 
$\mathrm{MSFE}_{i}^{k}-t$ statistic for a zero coefficient based on the Newey and West (1987) estimator. But the asymptotic distribution of the statistic is nonstandard under the null hypothesis as shown by Clark and McCracken (2001). Hence, we compare $\mathrm{MSFE}_{i}^{k}-t$ statistic for a zero coefficient with one-sided (to the right) critical values obtained using 10,000 fixed regressor bootstrap replications on a pairwise basis as in Clark and McCracken (2012). Further to address multiple-testing problem in light of data mining, we compute $\max _{i=3,4 \ldots, 15} \mathrm{MSFE}_{i}^{k}$ - $t$ statistic for reality check (i.e., best model) following Clark and McCracken (2012). In this case, one-sided (to the right) critical values are obtained using 10,000 fixed regressor bootstrap replications modified to account for multiple competing models nesting the benchmark. Under the composite null hypothesis, there is no predictive ability across all competing models. Therefore, rejection of the null hypothesis suggests that at least one competing model generates forecasts more accurate than the benchmark random walk with drift model. The bootstrap algorithm to obtain critical values for both pairwise and reality check tests are summarized in the Appendix A.

The second test that we employ is proposed by Giacomini and White (2006). This extremely powerful test covers a wide range of environments while asymptotically preserving the finite sample properties of the estimators upon which the forecasts may depend. In particular, the test: (1) is applicable to forecasts based on both nested and nonnested models; (2) captures the effect of estimation uncertainty (i.e., model misspecification due to unmodeled dynamics, unmodeled heterogeneity, and incorrect functional form) on relative forecast performance; (3) accommodates general estimation procedures including Bayesian and semi- and nonparametric methods to produce forecasts; and (4) is relatively easy to implement. However, the weakness of the test is that it applies to a rolling forecasting scheme with bounded estimation window size $M \leqslant P_{k}<\infty$. The null hypothesis is

$$
\mathrm{H}_{0}: E\left[\left(\Delta s_{t+1}^{k}-\Delta \tilde{s}_{t+1 \mid t}^{k}\right)^{2}-\left(\Delta s_{t+1}^{k}-\Delta \hat{s}_{i, t+1 \mid t}^{k}\right)^{2} \mid \mathcal{G}_{t}^{k}\right]=0
$$

where $\Delta s_{t+1}^{k}$ is the realized exchange rate return, $\Delta \tilde{s}_{t+1 \mid t}^{k}$ is the one-month ahead unconditional forecast from the random walk with drift benchmark, and $\Delta \hat{s}_{i, t+1 \mid t}^{k}$ is the one-month ahead forecast from a competing linear factor model specified in equation $(i)(i=3,4, \ldots, 15)$ that uses unconditional or conditional expectations of currency-based risk factors. ${ }^{10}$ In other words, the null hypothesis states that it is not possible to predict which forecast will be more accurate at a future date (in our case, month $t+1$ ) conditional on information set $\mathcal{G}_{t}^{k}$. For a given loss function and a given $\sigma$-field $\mathcal{G}_{t}^{k}$, the null hypothesis of equal conditional predictive ability is

\footnotetext{
${ }^{10}$ For the out-of-sample forecasts at the portfolio-level, $j,{\overline{\Delta s_{t+1}}}^{j}, \widetilde{{\overline{\Delta s_{t+1}}}^{j} t}$, and $\overline{{\overline{\Delta s_{i, t+1}}}^{j} \mathrm{t}}$ replace $k, \Delta s_{t+1}^{k}$, $\Delta \tilde{s}_{t+1 \mid t}^{k}$, and $\Delta \hat{s}_{i, t+1 \mid t}^{k}$, respectively.
} 
simply

$$
\mathrm{H}_{0}: E\left[\Delta L_{i, M, t+1}^{k} \mid \mathcal{G}_{t}^{k}\right]=0 .
$$

Under the null hypothesis, when $\mathcal{G}_{t}^{k}=\mathcal{F}_{t}^{k}$-measurable, $\left\{\Delta L_{i, M, t+1}^{k}, \mathcal{F}_{t}^{k}\right\}$ is a martingale difference sequence. This implies that the null hypothesis given by equation (20) can be expressed as

$$
\mathrm{H}_{0, q_{i}^{k}}: E\left[q_{i, t}^{k} \Delta L_{i, M, t+1}^{k}\right]=0
$$

for all $\mathcal{F}_{t}^{k}$-measurable functions $q_{t}^{k}$.

Utilizing the standard asymptotic normality argument, the test statistic for one-step ahead conditional predictive ability can be computed as $\left(P_{k}-1\right) R_{u c}^{2, k}$, where $R_{u c}^{2, k}$ is the uncentered squared multiple correlation coefficient from the regression of $\Delta L_{i, M, t+1}^{k}$ on $q_{i, t}^{k}$ '. Similar to the empirical example provided in Giacomini and White (2006), we use $q_{i, t}^{k}=\left(1, \Delta L_{i, M, t}^{k}\right)^{\prime}$. The null hypothesis of equal conditional predictive ability is rejected at the $\alpha$-level of significance if $\left(P_{k}-1\right) R_{u c}^{2, k}$ is greater than the $(1-\alpha)$ quantile of a $\chi_{2}^{2}$ distribution. But rejection of the null hypothesis does not automatically specify which model yields lower loss (or, equivalently, better forecast) at a future date. The decision rule is based on the fitted values from the regression of $\Delta L_{i, M, t+1}^{k}$ on $q_{i, t}^{k \prime}$. Following Giacomini and White (2006), in case of a rejection of the null hypothesis, a competing linear factor model is chosen over the random walk with drift benchmark if the fitted values are positive more than $50 \%$ of the time. Otherwise, the benchmark is chosen.

\subsection{Economic Measures of Forecast Accuracy}

Consistent with the recent literature (e.g., Rime et al. (2010), Della Corte et al. (2009, 2011), Della Corte and Tiakas (2012), Thornton and Valente (2012), and Nucera and Valente (2013)), we formulate an international asset allocation strategy based on the mean-variance efficient portfolio analysis. The framework involves trading the USD and the available sample of foreign currencies. The idea is to explore whether forecasts from linear factor models using currency-based risk factors, namely DOL, HML, and VOL, deliver a better asset allocation strategy in terms of economic performance measures.

To implement this, we consider an investor who, on a monthly basis, follows a simple twostep procedure. The first step involves producing one-month ahead forecasts of exchange rate returns using empirical models outlined in equations (2)-(15). In the second step, conditional on the forecasts from each model, the investor dynamically rebalances portfolio by optimally allocating his wealth between a domestic and $K$ foreign bonds. The objective is to maximize 
conditional expected return subject to achieving a given target of conditional volatility. ${ }^{11}$ As comparable monthly yield data are unavailable, we exploit CIP implied foreign risk-free nominal interest rates $i_{t}^{*} \approx s_{t}-f_{t}+i_{t}$ to proxy for the yields of foreign bonds. ${ }^{12}$ At the end of each month $t+1$, the foreign currency denominated bonds yield a risk-free return in local currency but a risky return $r_{t+1}$ in USD. The expectation of this risky return at the end of month $t$ is simply $E_{t}\left[r_{t+1}\right]=i_{t}^{*}+\Delta s_{t+1 \mid t}$. This implies that the asset allocation strategy exposes the US investor only to FX risk.

The estimation of the dynamic weights of the efficient portfolio, in general, requires onemonth ahead forecasts of the conditional mean and the conditional variance-covariance matrix. To illustrate, let $r_{t+1}$ denote the $K \times 1$ vector of risky asset (foreign bond) returns; $\mu_{t+1 \mid t}=$ $E_{t}\left[r_{t+1}\right]$ is the conditional expectation of $r_{t+1}$; and $V_{t+1 \mid t}=E_{t}\left[\left(r_{t+1}-\mu_{t+1 \mid t}\right)\left(r_{t+1}-\mu_{t+1 \mid t}\right)^{\prime}\right]$ is the conditional variance-covariance matrix of $r_{t+1}$. At the end of each month $t$, the investor solves the following problem:

$$
\begin{array}{ll}
\max _{w_{t}} & \left\{\mu_{p, t+1 \mid t}=w_{t}^{\prime} \mu_{t+1 \mid t}+\left(1-w_{t}^{\prime} \iota\right) i_{t}\right\} \\
\text { s.t. } & \left(\sigma_{p}^{*}\right)^{2}=w_{t}^{\prime} V_{t+1 \mid t} w_{t},
\end{array}
$$

where $\mu_{p, t+1 \mid t}$ is the conditional expected return of the portfolio, $w_{t}$ is the $K \times 1$ vector of time-varying portfolio weights on the risky assets, $\sigma_{p}^{*}$ is the target conditional volatility for the portfolio returns, and $\iota$ is the $K \times 1$ vector of ones. The solution to this constrained optimization problem delivers the following weights on the risky assets,

$$
w_{t}=\frac{\sigma_{p}^{*}}{\sqrt{C_{t}}} V_{t+1 \mid t}^{-1}\left(\mu_{t+1 \mid t}-\iota i_{t}\right)
$$

where $\mu_{t+1 \mid t}-\imath i_{t}$ is the $K \times 1$ vector of FX excess returns in USD and $C_{t}=\left(\mu_{t+1 \mid t}-\right.$ $\left.\iota i_{t}\right)^{\prime} V_{t+1 \mid t}^{-1}\left(\mu_{t+1 \mid t}-\iota i_{t}\right)$. The time-varying weight on the domestic risk-free asset is $1-w_{t}^{\prime} \iota$. Consistent with the literature (e.g., Welch and Goyal (2008), Ferreira and Santa-Clara (2011), and Thornton and Valente (2012)), we winsorize the weights as $-\iota \leqslant w_{t} \leqslant 2 \iota$ to prevent extreme investments while conducting the empirical analysis. The gross return on the investor's optimal portfolio is then

$$
R_{p, t+1}=1+r_{p, t+1}=1+\left(1-w_{t}^{\prime} \iota\right) i_{t}+w_{t}^{\prime} r_{t+1}
$$

In the dynamic optimization, we assume that $V_{t+1 \mid t}=\bar{V}$, where $\bar{V}$ is the unconditional

\footnotetext{
${ }^{11}$ The maximum expected return strategy is most often used for active currency management (Della Corte and Tiakas (2012)). However, the mean-variance efficient framework may involve dynamic asset allocation strategies to maximize expected utility and minimize volatility.

${ }^{12}$ To avoid clustering of notations in this subsection, we omit indexing empirical models and currencies by $i$ and $k$, respectively.
} 
variance-covariance matrix of exchange rate returns. This results in optimal weights $w_{t}$ to vary across empirical models only to the extent that they generate better forecasts of exchange rate returns. In the empirical estimation, we resort to a simple rolling estimate of $\bar{V}$ with eight-year window due to the unbalanced currency data available for our empirical analysis. ${ }^{13}$

Once portfolio returns are computed, we assess the economic value of predictability using several indicators proposed in the literature on the assessment of portfolio performance. The first measure is represented by the Sharpe ratio. This widely used risk-adjusted performance measure is built upon the mean-variance theory and is defined as follows:

$$
\text { Sharpe Ratio : } \frac{\overline{r_{p}-i}}{\sigma_{p}}
$$

where $\overline{r_{p}-i}$ is the realized average excess return on a portfolio and $\sigma_{p}$ is the standard deviation of the corresponding portfolio returns. A notable caveat for the Sharpe ratio is that it can underestimate the performance of a dynamically managed optimal portfolio (Marquering and Verbeek (2004) and Han (2006)). This is due to the overestimation of the conditional risk (standard deviation) faced by a risk averse investor at each point in time.

Second, we adopt the Sortino ratio, which measures the excess return to bad volatility. This ratio differentiates between volatility due to upside and downside movements in portfolio returns. The Sortino ratio is given by

$$
\text { Sortino Ratio : } \frac{\overline{r_{p}-i}}{\sigma_{p}^{-}}
$$

where $\sigma_{p}^{-}=\sigma\left(r_{p}<0\right)$ is the downside risk. It implies that the Sortino ratio does not take into account of positive returns while computing volatility. A large Sortino ratio is indicative of a low risk of large losses.

The third performance measure has been gaining popularity in the literature recently (e.g., Fleming et al. (2001), Della Corte et al. (2009, 2011), Rime et al. (2010), and Thornton and Valente (2012)). We calculate the out-of-sample performance fee to compare economic gains from using forecasts on exchange rate returns based on risk factors. This measure is built on mean-variance analysis with quadratic utility. ${ }^{14}$ We begin with the generalization of West et al.

\footnotetext{
${ }^{13}$ As in Fleming et al. (2001) and Thornton and Valente (2012), we also consider a rolling sample variance estimator that places exponentially declining weights for observations progressively going backwards. This procedure does not change the economic value results qualitatively.

${ }^{14}$ The assumption of a quadratic utility function is appealing since it: (1) justifies the mean-variance framework when return distributions are nonnormal; and (2) provides a high degree of analytical tractability.
} 
(1993) showing that the average realized utility to an investor with initial wealth $W_{0}$ is

$$
\bar{u}(.)=\frac{W_{0}}{P} \sum_{t=M+1}^{T-1}\left(R_{p, t+1}-\frac{\gamma}{2(1+\gamma)} R_{p, t+1}^{2}\right),
$$

where $\gamma$ is the investor's degree of relative risk aversion. Equation (27) implies that for a given $\gamma$ and a given level of wealth $W_{0}$, at any point in time one set of conditional return estimates is preferred to an alternative set provided that investment decisions based on the first set leads to higher average realized utility $\bar{u}($.$) .$

Combined with the work of Fleming et al. (2001), the performance fee $\Phi$ is computed by equating the average realized utilities of the optimal portfolios for the random walk with drift benchmark and the selected competing model. In particular, the performance fee is obtained as the value of $\Phi$ that satisfies the following:

$$
\begin{aligned}
& \sum_{t=M+1}^{T-1}\left\{\left(R_{p, t+1}^{*}-\Phi\right)-\frac{\gamma}{2(1+\gamma)}\left(R_{p, t+1}^{*}-\Phi\right)^{2}\right\}= \\
& \sum_{t=M+1}^{T-1}\left\{R_{p, t+1}-\frac{\gamma}{2(1+\gamma)} R_{p, t+1}^{2}\right\} .
\end{aligned}
$$

In equation (28), $R_{p, t+1}^{*}$ and $R_{p, t+1}$ denote the gross portfolio returns constructed using forecasts from a competing linear factor model and the benchmark, respectively. The performance fee $\Phi$ has a natural interpretation: it is the maximum fee a risk averse investor would be willing to pay to switch from the random walk with drift benchmark to the competing model strategy. Note that if there is no predictive power embedded in currency-based risk factors, then $\Phi \leqslant 0$. In contrast, $\Phi>0$ if the risk factors do help produce more accurate exchange rate forecasts.

Fourth, we also compute performance fee $\Psi$ by considering a mean-variance utility function. Within this framework, the average realized utility to an investor is

$$
\bar{u}_{M V}(.)=\bar{R}_{p}-\frac{\gamma}{2 P} \sum_{t=M+1}^{T-1}\left(R_{p, t+1}-\bar{R}_{p}\right)^{2},
$$

where $\bar{R}_{p}=\frac{1}{P} \sum_{t=M+1}^{T-1} R_{p, t+1}$. The performance fee $\Psi$ is obtained as

$$
\Psi=\bar{u}_{M V}\left(R_{p, t+1}^{*}\right)-\bar{u}_{M V}\left(R_{p, t+1}\right)
$$

Finally, to facilitate comparison between portfolios based on forecasts from random walk with drift benchmark and a competing model, we implement the manipulation-proof performance measure introduced by Goetzmann et al. (2007). This performance criterion for risk- 
adjusted excess return is defined as

$$
\Theta=\frac{1}{1-\gamma} \ln \left[\frac{1}{P} \sum_{t=M+1}^{T-1}\left(\frac{R_{p, t+1}^{*}}{R_{p, t+1}}\right)^{1-\gamma}\right]
$$

Unlike the performance fee $\Phi$, the manipulation-proof performance measure $\Theta$ does not depend on the restrictive assumption of a quadratic utility to rank portfolios and it is robust to the distribution of portfolio returns. The measure can be interpreted as the certainty equivalent of the excess portfolio returns. Hence, it is the maximum performance fee a risk averse investor will pay to switch from the random walk with drift benchmark to the competing model strategy.

\section{Empirical Results}

In this section, we describe the data used for the empirical analysis. We then focus on the statistical evaluation and economic value analysis, respectively, of the out-of-sample forecasts from the linear factor models for exchange rate returns. A number of extensions of the baseline results on statistical evaluation are also analyzed as robustness measures.

\subsection{Data}

The data consist of midpoint of bid and ask quotes for daily spot and one-month forward exchange rates collected from Barclays Bank International (BBI) and World Markets PLC/Reuters (WMR) via the Datastream. The sample period for individual currencies is from November 1983 to November 2013. We conduct empirical analysis using exchange rates expressed as units of USD per foreign currency unit for the full cross-section and sample period. To construct the time-series to proxy for global FX volatility, we use midpoint spot quotes at daily frequency covering the sample period from November 1, 1983 to November 29, 2013. But we compute the nonoverlapping monthly return and excess return series for individual currencies using the end-of-month (last trading day) observations. The sample for empirical analysis contains currencies from 16 developed and developing countries. The developed countries include Australia, Canada, Germany $\backslash$ Euro area, Japan, New Zealand, Sweden, Switzerland, and the United Kingdom. ${ }^{15}$ A notable characteristic of this subsample is that it includes the most liquid currencies in the FX market. The developing countries include the Czech Republic, Hungary, India, Philippines, Singapore, South Africa, Taiwan, and Thailand. We only choose countries with floating or least controlled exchange rate regimes over most of the sample period. Note that the sample

\footnotetext{
${ }^{15}$ Data for Germany after December 1998 are constructed using the euro/USD exchange rate and the official fixed conversion rate of 1.95583 Deutsche Mark/euro.
} 
is an unbalanced panel data.

The number of currencies increases as data on more currencies from developing countries become available. The total number of currencies used to build forward discount-sorted portfolios varies over the sample period with a minimum of 7 and a maximum of 16 . In addition, we consider currencies for which both spot and one-month forward exchange rates are available for at least 16 years due to data requirements for the empirical analysis. It is worth noting that the sample covers all of the pronounced financial market turmoils in the past three decades including the financial and banking crisis of 2007-2008. Table 1 provides a detailed description of data sources and summary statistics of individual currencies. We obtain the US risk-free interest rate at the end of each month expressed as a monthly rate from the Internet Data Library maintained by Kenneth French. ${ }^{16}$ The risk-free interest rate corresponds to the one-month Treasury bill rate provided by Ibbotson and Associates, Inc. These data serve as a reasonable proxy for domestic nominal risk-free interest rate.

\subsection{Out-of-Sample Predictions}

We begin the empirical analysis with the unconditional expectations of the currency-based risk factors under the rolling forecasting scheme. Table 2 presents the results for the out-ofsample forecast accuracy of the linear factor models relative to the benchmark for 16 individual currencies. The one-month ahead forecasts of exchange rate returns are from November 1991 to November 2013. In Panel A, we notice that for currencies from eight developed countries, the Diebold and Mariano (1995) and West (1996) test for pairwise forecast comparison rarely rejects the null hypothesis of equal MSFE at the $10 \%$ significance level. Similar finding emerges for the conditional predictive ability test of Giacomini and White (2006), which fails to reject the null hypothesis of equal conditional predictive ability at the $10 \%$ significance level and to choose a competing model over the benchmark. Looking at Panel B, which reports results for currencies from eight developing countries, we observe a marginally improved picture. A number of competing linear factor models significantly outperform the random walk with drift benchmark for few currencies. For example, considering the Diebold and Mariano (1995) and West (1996) test applied on a pairwise basis, four out of ten competing models for Singapore and South Africa and eight out of ten models for Taiwan significantly outperform the benchmark. Moreover, for Taiwan, the Giacomini and White (2006) test rejects the null hypothesis of equal conditional predictive ability at the $10 \%$ significance level and chooses eight out of ten competing models over the benchmark. However, focusing on the reality check version of the Diebold and

\footnotetext{
${ }^{16}$ For details, see http://mba.tuck.dartmouth.edu/pages/faculty/ken.french/data_library.html.
} 
Mariano (1995) and West (1996) test following Clark and McCracken (2012), which compares the best competing model with the benchmark, only Taiwan exhibits statistical significance at the $10 \%$ level. This implies that at least one competing linear factor model for Taiwan, which is the model given by equation (6), is strictly superior to that of the random walk with drift benchmark.

In Table 3, we report the out-of-sample forecast evaluation metric based on the unconditional expectations of the risk factors under the recursive scheme. For the Diebold and Mariano (1995) and West (1996) test employed on a pairwise basis, we see a few competing models outperforming the benchmark for currencies from developing countries such as Philippines, Singapore, South Africa, Taiwan, and Thailand. With the exception of Singapore and South Africa, the statistical significance in the pairwise test does not hold up under the reality check version of the Diebold and Mariano (1995) and West (1996) test. This shows evidence of some degree of predictability across the liner factor models of exchange rate returns for these two countries only.

Tables 4 and 5 present the results for the forecasting exercises using the conditional expectations of the currency-based risk factors under the rolling and recursive schemes, respectively. Notably, the Diebold and Mariano (1995) and West (1996) test for pairwise forecast comparison occasionally rejects the null hypothesis of equal MSFE at the $10 \%$ significance level. With few exceptions, the Giacomini and White (2006) test of equal conditional predictive ability also fails to reject the null hypothesis at the $10 \%$ significance level and to choose a competing model over the benchmark. The results from these two statistical evaluation metrics corroborate each other. We report the results for the out-of-sample forecasts at the portfolio-level based on the unconditional expectations of the risk factors under the rolling and recursive schemes in Tables 6 and 7, respectively. The primary conclusion based on the relative performance of the linear factor models is invariant to that of the individual currencies. ${ }^{17}$

A careful examination of the results presented in Tables $2-5$ convey the following key messages. First, considering the rolling forecasting scheme and the reality check test, none of the competing linear factor models using the conditional expectations of the currency-based risk factors dominates the benchmark. With the exception of Taiwan, this observation holds for the competing models utilizing the unconditional expectations of the risk factors. Moving on to the recursive forecasting scheme, South Africa is the only country for which linear factor models show significant predictability irrespective of forecasts using unconditional and conditional expectations of currency-based risk factors. Linear factor model given by equation (8) show predictability for Singapore when forecasts of exchange rate returns are obtained using

\footnotetext{
${ }^{17}$ The results for the out-of-sample forecasts at the portfolio-level based on the conditional expectations of the risk factors are qualitatively the same. They are available upon request from the authors.
} 
unconditional expectations of risk factors. Hence, there is compelling evidence of no predictive ability for most currencies in our sample.

Second, linear factor models that use unconditional expectations of risk factors, in general, produce relatively better forecasts of exchange rate returns. This echoes findings in similar out-of-sample forecasting exercises in the equity market. Notably, Simin (2008) shows that incorporating information in conditional expectations of state variables produces poor forecasts in the context of Fama and French (1993) 25 size and book-to-market equity portfolios. Also related, Welch and Goyal (2008) argue that no economic variable helps forecast the US equity premium regardless of the forecasting horizon in the out-of-sample tests.

To sum up, the out-of-sample results in Tables 2-7 clearly indicate a lack of short-horizon predictive ability prowess in the currency-based risk factors that are found to have in-sample time-series and cross-sectional explanatory power. ${ }^{18}$ Said differently, results based on one-month ahead forecasts from linear factor models for exchange rate returns are unequivocally frail. The models do not produce forecasts better than the random walk with drift benchmark. This echoes the empirical dominance of the random walk model in exchange rate forecasting. Overall, the empirical findings emerged from the statistical tests are consistent with Simin (2008), who shows poor predictive performance of asset pricing models for equity returns.

\subsection{Robustness}

\section{Forecasts with Combined Schemes}

We examine whether the out-of-sample forecast accuracy of the linear factor models relative to the benchmark random walk with drift model improves when the rolling and recursive scheme forecasts are combined. Recently, Clark and McCracken (2009) show a procedure to compute the optimal forecast combination weights $\theta$ and $(1-\theta)$ for the recursive and rolling forecasting schemes, respectively. We follow their methodology and obtain three values for the combination weight $\theta$. These are $0.92,0.96$, and 0.98 , which we compute under the assumptions of potential structural changes in the slope coefficients of the linear factor model regressions of $80 \%, 50 \%$, and $30 \%$, respectively. The one-month ahead combined forecasts of exchange rate returns for 16 individual currencies come from recursive regressions with a eight-year starting expanding window and rolling regressions with a eight-year window using weights $\theta$ and $(1-\theta)$, respectively.

To assess the accuracy of the forecasts combined in the above manner, we compute the Theil (1996) U-statistic. More precisely, the statistic is the ratio of the root MSFE (RMSFE) of a

\footnotetext{
${ }^{18}$ Our findings remain invariant while exploiting the Campbell and Thompson (2008) measure of out-of-sample $R^{2}$ statistic, the Clark and West $(2006,2007)$ test for pairwise forecast comparison and the associated reality check test following Clark and McCracken (2012). These results are available upon request from the authors.
} 
competing model to the RMSFE of the benchmark and is given by

$$
\mathrm{U}_{i}^{k}=\sqrt{\frac{\sum_{t=M+1}^{T_{k}-1}\left(\Delta s_{t+1}^{k}-\Delta \hat{s}_{i, t+1 \mid t}^{k, c o m b}\right)^{2}}{\sum_{t=M+1}^{T_{k}-1}\left(\Delta s_{t+1}^{k}-\Delta \tilde{s}_{t+1 \mid t}^{k, c o m b}\right)^{2}}},
$$

where $\Delta \tilde{s}_{i, t+1 \mid t}^{k, c o m b}$ and $\Delta \hat{s}_{i, t+1 \mid t}^{k, c o m b}$ are the one-month ahead unconditional and conditional forecasts from the random walk with drift benchmark and a competing linear factor model in equation (i) $(i=3,4, \ldots, 15)$, respectively. The null hypothesis is that the competing model and the benchmark generate equally accurate forecasts, i.e., $\mathrm{U}_{i}^{k}=1$. The alternative hypothesis states that the competing model provides more accurate forecasts than the benchmark, i.e., $\mathrm{U}_{i}^{k}<1$. One-sided (to the left) critical values are obtained using the fixed regressor bootstrap procedure with 10,000 replications on a pairwise basis as in Clark and McCracken (2012).

Tables A1 and A2 in the Appendix summarize the combined forecasting results when $\theta$ is 0.92 for the unconditional and conditional expectations of the currency-based risk factors. A careful review of these results suggests that the out-of-sample relative forecast accuracy does not improve with the combined weighting schemes and our baseline results on the predictive ability of the risk factors still hold. ${ }^{19,20}$ In addition, we find no obvious evidence that our linear factor models experience structural changes.

\section{Purchasing Power Parity Benchmark}

Considering the difficulty of empirically beating the random walk with drift benchmark, we also compare forecasts from the linear factor models against the relatively successful PPP fundamentals documented in the literature (e.g., Della Corte and Tiakas (2012) and GreenawayMcGrevy et al. (2014)). This alternative benchmark model based on the PPP hypothesis is given by

$$
\Delta s_{t}^{k}=a_{0}^{k}+d_{0}^{k}\left(p_{t-1}-p_{t-1}^{k}-s_{t-1}^{k}\right)+e_{t}^{k}
$$

where $p_{t}$ and $p_{t}^{k}$ denote the logs of the price levels in the domestic country and the foreign country corresponding to currency $k$, respectively, in month $t .^{21}$ The PPP hypothesis, due to

\footnotetext{
${ }^{19}$ Following the methodology in Clark and West (2006, 2007), we also estimate bias adjusted Theil (1996) U-statistic and find qualitatively similar results.

${ }^{20}$ The empirical results based on $\theta=0.96$ and $\theta=0.98$ are qualitatively the same. They are available upon request from the authors.

${ }^{21}$ The price level for each country is empirically proxied by the corresponding consumer price index (CPI) of the country. Except for Germany $\backslash$ Euro Area and the United Kingdom, data on CPI at a monthly frequency are from the International Financial Statistics prepared by the International Monetary Fund (base year, 2010=100). The data for Germany $\backslash$ Euro Area and the United Kingdom are obtained from the Organization for Economic Cooperation and Development database (base year, $2010=100$ ). We exclude Taiwan from the out-of-sample forecasting exercises due to the lack of comparable CPI data over our sample period. In addition, CPI for Australia and New Zealand are available only in quarterly frequency. We convert these time-series to a monthly
} 
Cassel (1918), states that two relevant national price levels should be the same when expressed in a common currency. This is likely to hold only in the long-run (e.g., Taylor and Taylor (2004)).

In order to determine the out-of-sample predictive power of the factor models relative to the PPP benchmark, we continue to exploit the Diebold and Mariano (1995) and West (1996) MSFE $t$-statistic. But the alternative hypothesis in this case is two-sided. A positive (negative) and statistically significant MSFE $t$-statistic for a zero coefficient indicates that the competing model outperforms (is outperformed by) the PPP benchmark. Moreover, the test statistic follows an asymptotic standard normal distribution under the null hypothesis since our competing linear factor models do not nest the PPP benchmark. Therefore, we use standard normal critical values for valid inference. Following the suggestion in Clark and McCracken (2013), we compute the Diebold and Mariano (1995) and West (1996) $\mathrm{MSFE}_{i}^{k}-t$ statistic using the prewhitened quadratic spectral variance estimator developed by Andrews and Monahan (1992).

The empirical results are summarized in Tables A3 and A4 in the Appendix based on the unconditional expectations of the risk factors under the rolling and recursive forecasting schemes, respectively. We observe that there is little evidence that the benchmark PPP model is outperformed by the competing linear factor models in the out of sample. ${ }^{22}$ Only for Thailand, any factor models beat the benchmark when forecasts are assessed on the Diebold and Mariano (1995) and West (1996) MSFE $t$-statistic. Excluding Australia, Canada, Japan, and South Africa, the Giacomini and White (2006) test also fails to reject the null hypothesis of equal conditional predictive ability at the $10 \%$ significance level and to choose a competing model over the benchmark. Overall, the out-of-sample evidence, which is consistent with our baseline results in Section 4.2, suggests frailty in predictive power of currency-based risk factors.

\section{Long-Horizon Forecasts}

Finally, we investigate the long-horizon forecasting power of the currency-based risk factors by conducting $l$-month ahead forecasting exercises. The model specifications are still given by equations (2)-(15), except that $s_{t}^{k}-s_{t-l}^{k}$ and $z_{t-l}^{k}$ replace $\Delta s_{t}^{k}$ and $z_{t-1}^{k}$, respectively. Accordingly, unconditional and conditional forecasts of risk factors in the out-of-sample period are obtained by methods similar to those of one-month ahead forecasting except that $D O L_{t}, H M L_{t}$, and $V O L_{t}$ are regressed on a constant and $z_{t-l}^{k}$ when forming conditional factor expectations. We

frequency using linear interpolation. The choice of the interpolation method has an immaterial effect on our empirical results. Finally, all CPI data exploited in the empirical analysis are adjusted for seasonality.

${ }^{22}$ Similar conclusion emerges when the factor models use the conditional expectations of the currency-based risk factors under the rolling and recursive forecasting schemes. These results are available upon request from the authors. 
consider 12 and 24 months for the values of the forecast horizon $l$. One-sided (to the right) critical values for both pairwise and reality check tests are obtained using 10,000 fixed regressor bootstrap replications as in Clark and McCracken (2012).

We report the results in Tables A5 and A6 in the Appendix, which are based on the unconditional and conditional expectations of the risk factors, respectively, under a rolling forecasting scheme. Focusing on the unconditional expectations of the factors and the 12-month horizon, the Diebold and Mariano (1995) and West (1996) test for pairwise forecast comparison rejects the null hypothesis of equal MSFE at the 10\% significance level only for Canada, the Czech Republic, and South Africa. Except for the Czech Republic, these pairwise results do not hold up under the reality check version of the test. At the 24-month horizon, a handful number of competing linear factor models significantly outperform the random walk with drift benchmark for India only. However, the statistical significance in the pairwise case disappears under the reality check microscope. ${ }^{23}$ Hence, the robustness test that focuses on the long-horizon forecasts supports our baseline finding of weak predictive ability of the currency-based risk factors.

\subsection{Economic Value of Return Predictability}

The weak statistical performance does not necessarily indicate poor economic significance in the out of sample. Therefore, in this subsection we analyze results from out-of-sample economic value of exchange rate predictability. We focus on the performance of a set of dynamically rebalanced portfolios that utilize one-month ahead forecasts from the empirical models given by equations $(2)-(15)$. The forecasts of exchange rate returns are generated using parameters estimated by a rolling scheme with a eight-year window. Moreover, the rolling forecasting scheme considers both unconditional and conditional expectations of currency-based risk factors. The out-of-sample economic value analysis is from November 1991 to November 2013. Once again, we use a dynamic portfolio strategy based on the random walk with drift model as the benchmark to compare economic performance of the competing portfolio strategies. Each portfolio corresponds to a maximum expected return strategy with a target annualized volatility of $\sigma_{p}^{*}=10 \%$. The empirical assessment of economic value focuses on five performance criteria, namely, the Sharp ratio, the Sortino ratio, the Fleming et al. (2001) measure of performance fee $\Phi$, the mean-variance utility based performance fee $\Psi$, and the Goetzmann et al. (2007) manipulation-proof measure of performance fee $\Theta$. We set the degree of relative risk aversion $\gamma=6$ in the computation of performance fees $\Phi, \Psi$, and $\Theta$. The choice of $\sigma_{p}^{*}$ and $\gamma$ is in line with the values adopted in the recent literature (e.g., Fleming et al. (2001), Marquering and

\footnotetext{
${ }^{23}$ Our findings hold under the Clark and West $(2006,2007)$ test for pairwise forecast comparison and the associated reality check test. These results are available upon request from the authors.
} 
Verbeek (2004), Della Corte et al. (2009, 2011) and Della Corte and Tiakas (2012)).

Table 8 summarizes empirical results based on spot exchange rates of 16 foreign currencies from developed and developing countries in Panel A. Focusing on portfolio strategies that use unconditional expectations of risk factors, we observe that the random walk with drift strategy delivers an out-of-sample annualized Sharpe ratio of 0.97 , which is the highest among all strategies. In terms of annualized Sortino ratio, strategies based on linear factor models given by all but equation (7) fail to generate improved performance over the benchmark. The annualized performance fees $\Phi$ and $\Psi$ expressed in decimals (i.e., $0.01=1$ annual percentage point) are negative when switching from the random walk with drift benchmark to any competing portfolio strategies. The values of $\Phi$ and $\Psi$ range between $-5 \%$ and $-1 \%$ per annum. Similar picture emerges for the annualized manipulation-proof performance fee $\Theta$, which ranges between $-7 \%$ and $-1 \%$. For strategies that exploit conditional expectations of risk factors, we once again find that the Sharpe ratio due to the random walk with drift strategy outperforms all competing strategies. In general, the Sharpe ratios for portfolio strategies utilizing conditional expectations of factors are higher than those obtained for portfolio strategies using unconditional expectations of risk factors. Portfolio strategy based on the random walk with drift benchmark delivers the highest annualized Sortino ratio of 1.34. The performance fees $\Phi$ and $\Psi$ for switching from the random walk with drift strategy to a competing strategy is negative. The manipulation-proof performance fees $\Theta$ are all negative and range between $-7 \%$ and $-2 \%$ per annum. These results reflect the fact that linear factor models with currency-based risk factors do not outperform the random walk with drift benchmark even in the context of out-of-sample economic value. Put differently, information content embedded in DOL, HML, and VOL factors does not generate systematic economic value to a risk averse investor.

The economic value analysis reported so far is based on an unbalanced panel data of currencies. For robustness, we also conduct the dynamic asset allocation exercise using a smaller but nearly balanced subsample of the eight developed countries. Panel B summarizes the economic value assessment of this smaller subsample. For portfolio strategies using unconditional expectations of risk factors, we notice that the random walk with drift strategy delivers an outof-sample annualized Sharpe ratio of 0.47. The point estimate is higher than those obtained for all other competing strategies. The random walk with drift strategy also outperforms all competing strategies by generating the highest annualized Sortino ratio of 0.56. Switching from the benchmark random walk with drift strategy to any competing portfolio strategies generates negative performance fees $\Phi$ and $\Psi$ and manipulation-proof performance fee $\Theta$. They range between $-5 \%$ and $-1 \%$ for $\Phi$ and $\Psi$, while $-7 \%$ and $-2 \%$ for $\Theta$ per annum. With the exception 
of Sharpe and Sortino ratios, we find similar evidence on economic value when portfolio strategies make use of conditional expectations of risk factors. Only in terms of Sharpe and Sortino ratios, portfolio strategies based on linear factor models given by equations (3)-(8), and (13)(15) show marginally better performance over the benchmark strategy. Overall, the results in Panel B qualitatively corroborate to those reported in Panel A. The out-of-sample portfolio performance suggests that there is little tangible economic value associated with the empirical linear factor models for exchange rate returns. This complements the evidence on the dominance of the random walk with drift benchmark over the linear factor models at short-horizon in the forecast evaluation metrics.

\section{Conclusion}

Exchange rate predictability has evolved as a major area of research in international finance. Central banks, academics, and practitioners are in the continuous search for models that can provide accurate and reliable forecasts of exchange rates both at short and long horizons. This paper explores time-series predictability of bilateral exchange rates from linear factor models using unconditional and conditional expectations of currency-based risk factors. The aim is to assess whether asset pricing models proposed in the recent literature are able to provide accurate expectations of future exchange rate returns.

Our empirical evidence suggests that the factor models hardly outperform the random walk with drift benchmark in the out-of-sample forecasting exercise for individual currencies. This finding remains the same at the portfolio-level when currencies are sorted on their forward discounts and it is not affected by the sample composition, the computation of factor expectations, the estimation methods and metrics of evaluation. Moreover, our results also show that the information content embedded in the currency-based risk factors does not generate systematic economic value to a risk averse investor who formulates dynamic portfolios conditional on the forecasts from the factor models. These results, albeit consistent with the overall message of Meese and Rogoff (1983a) study, also provide valuable implications for practitioners in the FX markets who require accurate forecasts of future exchange rate returns to design active currency management strategies. 


\section{Appendix A}

The fixed regressor bootstrap algorithm to generate critical values for pairwise and reality check test statistics follow Clark and McCracken (2012). ${ }^{24}$ The steps involving the algorithm are:

1. Use ordinary least squares (OLS) to estimate the parameters of the competing (unrestricted) model in equation $(i)(i=3,4, \ldots, 15)$. Store the residuals $\hat{e}_{t(l \geqslant 1)}, t=1,2, \ldots, T-l$, where $l$ is the forecast horizon. Only for the reality check test, estimate the parameters of the competing (unrestricted) model that includes all regressors considered across all models, i.e., the model given by equation (15). Store the corresponding residuals and follow the steps below.

2. If $l>1$, use nonlinear LS (NLLS) to estimate a moving average, $M A(l-1)$, model for the OLS residuals $\hat{e}_{t(l>1)}$ such that $e_{t(l>1)}=\varepsilon_{t}+\delta_{1} \varepsilon_{t-1}+\ldots+\delta_{l-1} \varepsilon_{t-l+1}$.

3. Use OLS to estimate the parameter of the benchmark (restricted) random walk with drift model in equation (2). Store the fitted values $\hat{\Delta} s_{t}, t=1,2, \ldots, T-1$. For $l>1$, the fitted values are $\left(\widehat{s_{t}-s_{t-l}}\right), t=1,2, \ldots, T-l$.

4. Let $\eta_{t}, t=1,2, \ldots, T-l$, denote an independently and identically distributed $\mathrm{N}(0,1)$ sequence of simulated random variables. If $l=1$, i.e., one-month ahead forecasting, define $\hat{e}_{t(l=1)}^{*}=\eta_{t} \hat{e}_{t(l=1)}, t=1,2, \ldots, T-1$. If $l>1$, define $\hat{e}_{t(l>1)}^{*}=\eta_{t} \hat{\varepsilon}_{t}+\hat{\delta}_{1} \eta_{t-1} \hat{\varepsilon}_{t-1}+\ldots+$ $\hat{\delta}_{l-1} \eta_{t-l+1} \hat{\varepsilon}_{t-l+1}, t=1,2, \ldots, T-l$.

5. Generate artificial samples of $\hat{\Delta} s_{t}^{*}$ using the fixed regressor structure, $\hat{\Delta} s_{t}^{*}=\hat{\Delta} s_{t}+\hat{e}_{t(l=1)}^{*}$. For $l>1$, generate $\left(\widehat{s_{t}-s_{t-l}}\right)^{*}=\left(\widehat{s_{t}-s_{t-l}}\right)+\hat{e}_{t(l>1)}^{*}$.

6. Using the artificial data, construct the out-of-sample forecasts and an estimate of the test statistics (e.g., $\mathrm{MSFE}_{i}-t$ and $\mathrm{U}_{i}$ for pairwise and $\underset{i=3,4 \ldots, 15}{\max } \mathrm{MSFE}_{i}-t$ for reality check tests) as if these were the original data.

7. Repeat steps 4-6 a large number of times, in our case, 10,000 replications.

8. For a one-sided to the right test (left test), reject the null hypothesis at the $\alpha \%$ level if the test statistic is greater (smaller) than the $(100-\alpha)$ percentile ( $\alpha$ percentile) of the empirical distribution of the simulated test statistics.

\footnotetext{
${ }^{24}$ For ease of illustration, we omit indexing currencies and portfolios by $k$ and $j$, respectively, while indexing empirical models by $i$ at minimum.
} 


\section{References}

Akram, F. Q., Rime, D., Sarno, L., 2008. Arbitrage in the foreign exchange market: Turning on the microscope. Journal of International Economics 76, 237-253.

Andrews, D. W. K., Monahan, C. J., 1992. An improved heteroskedasticity and autocorrelation consistent covariance matrix estimator. Econometrica 60, 953-966.

Backus, D. K., Foresi, S., Telmer, C. I., 2001. Affine term structure models and the forward premium anomaly. Journal of Finance 56, 279-304.

Berg, K. A., Mark, N. C., 2014. Third-country effects on the exchange rate, Working Paper, Department of Economics, University of Notre Dame.

Brennan, M. J., Xia, Y., 2006. International capital markets and foreign exchange risk. Review of Financial Studies 19, 753-795.

Campbell, J. Y., 1993. Intertemporal asset pricing without consumption data. American Economic Review 83, 487-512.

Campbell, J. Y., 1996. Understanding risk and return. Journal of Political Economy 104, 298345.

Campbell, J. Y., Thompson, S. B., 2008. Predicting excess stock returns out of sample: Can anything beat the historical average? Review of Financial Studies 21, 1509-1528.

Cassel, G., 1918. Abnormal deviations in international exchanges. Economic Journal 28, 413415.

Cheung, Y.-W., Chinn, M. D., Garcia Pascual, A., 2005. Empirical exchange rate models of the nineties: Are any fit to survive? Journal of International Money and Finance 24, 1150-1175.

Chinn, M. D., Meese, R. A., 1995. Banking on currency forecasts: How predictable is change in money? Journal of International Economics 38, 161-178.

Clark, T. E., McCracken, M. W., 2001. Tests of equal forecast accuracy and encompassing for nested models. Journal of Econometrics 105, 85-110.

Clark, T. E., McCracken, M. W., 2009. Improving forecast accuracy by combining recursive and rolling forecasts. International Economic Review 50, 363-395.

Clark, T. E., McCracken, M. W., 2012. Reality checks and comparisons of nested predictive models. Journal of Business \& Economic Statistics 30, 53-66. 
Clark, T. E., McCracken, M. W., 2013. Advances in forecast evaluation. In: Elliott, G., Timmermann, A. (Eds.), Handbook of Economic Forecasting. North Holland, New York.

Clark, T. E., West, K. D., 2006. Using out-of-sample mean squared prediction errors to test the martingale difference hypothesis. Journal of Econometrics 135, 155-186.

Clark, T. E., West, K. D., 2007. Approximately normal tests for equal predictive accuracy in nested models. Journal of Econometrics 138, 291-311.

Cochrane, J. H., 2001. A rehabilitation of the stochastic discount factor methodology, NBER Working Paper No. 8533.

Della Corte, P., Sarno, L., Tsiakas, I., 2009. An economic evaluation of empirical exchange rate models. Review of Financial Studies 22, 3491-3530.

Della Corte, P., Sarno, L., Tsiakas, I., 2011. Spot and forward volatility in foreign exchange. Journal of Financial Economics 100, 496-513.

Della Corte, P., Tiakas, I., 2012. Statistical and economic methods for evaluating exchange rate predictability. In: James, J., Marsh, I. W., Sarno, L. (Eds.), Handbook of Exchange Rates. John Wiley \& Sons, Hoboken.

Diebold, F. X., Mariano, R. S., 1995. Comparing predictive accuracy. Journal of Business \& Economic Statistics 13, 253-263.

Diebold, F. X., Nason, J. A., 1990. Nonparametric exchange rate prediction? Journal of International Economics 28, 315-332.

Engel, C., Hamilton, J. D., 1990. Long swings in the dollar: Are they in the data and do markets know it? American Economic Review 80, 689-713.

Engel, C., Mark, N. C., West, K. D., 2015. Factor model forecasts of exchange rates. Econometric Reviews 34, 32-55.

Engel, C., West, K. D., 2005. Exchange rates and fundamentals. Journal of Political Economy $3,485-517$.

Evans, M. D. D., Lyons, R. K., 2002. Order flow and exchange rate dynamics. Journal of Political Economy 110, 170-180.

Evans, M. D. D., Lyons, R. K., 2005. Meese-Rogoff redux: Micro-based exchange-rate forecasting. American Economic Review (Papers and Proceedings) 95, 405-414. 
Fama, E. F., French, K. R., 1993. Common risk factors in the returns on stocks and bonds. Journal of Financial Economics 33, 3-56.

Farnsworth, H., Ferson, W. E., David, J., Todd, S., 2002. Performance evaluation with stochastic discount factor. Journal of Business 75, 473-503.

Ferraro, D., Rogoff, K., Rossi, B., 2012. Can oil prices forecast exchange rates, Working Paper, Department of Economics, Duke University.

Ferreira, M. A., Santa-Clara, P., 2011. Forecasting stock market returns: The sum of the parts is more than the whole. Journal of Financial Economics 100, 514-537.

Fleming, J., Kirby, C., Ostdiek, B., 2001. The economic value of volatility timing. Journal of Finance 56, 329-352.

Giacomini, R., White, H., 2006. Tests of conditional predictive ability. Econometrica 74, 15451578.

Goetzmann, W., Ingersoll, J., Spiegel, M., Welch, I., 2007. Portfolio performance manipulation and manipulation-proof performance measures. Review of Financial Studies 20, 1503-1546.

Greenaway-McGrevy, R., Mark, N. C., Sul, D., Wu, J.-L., 2014. Exchange rates as exchange rate common factors, Working Paper, Department of Economics, University of Notre Dame.

Han, Y., 2006. Asset allocation with a high dimensional latent factor stochastic volatility model. Review of Financial Studies 19, 237-271.

Harvey, C. R., Siddique, A., 2000. Conditional skewness in asset pricing tests. Journal of Finance $55,1263-1295$.

Inoue, A., Kilian, L., 2004. In-sample or out-of-sample tests of predictability: Which one should we use? Econometric Review 23, 371-402.

Inoue, A., Kilian, L., 2006. On the selection of forecasting models. Journal of Econometrics 130, 273-306.

Jagannathan, R., Wang, Z., 1996. The conditional CAPM and the cross-section of expected returns. Journal of Finance 51, 3-53.

Kan, R., Zhou, G., 1999. A critique of the stochastic discount factor methodology. Journal of Finance 54, 1221-1248. 
Lintner, J., 1965. The valuation of risky assets and the selection of risky investments in stock portfolios and capital budgets. Review of Economics and Statistics 47, 13-37.

Lustig, H., Roussanov, N., Verdelhan, A., 2011. Common risk factors in currency markets. Review of Financial Studies 24, 3731-3777.

Mark, N. C., 1995. Exchange rates and fundamentals: Evidence on long-horizon predictability. American Economic Review 85, 201-218.

Marquering, W., Verbeek, M., 2004. The economic value of predicting stock index returns and volatility. Journal of Financial and Quantitative Analysis 39, 407-429.

McCracken, M. W., Valente, G., 2014. Asymptotic inference for performance fees and the predictability of asset returns, Working Paper, Department of Economics and Finance, City University of Hong Kong.

Meese, R. A., Rogoff, K., 1983a. Empirical exchange rate models of the seventies: Do they fit out of sample? Journal of International Economics 14, 3-24.

Meese, R. A., Rogoff, K., 1983b. The out-of-sample failure of empirical exchange rate models: Sampling error or misspecification. In: Frenkel, J. A. (Ed.), Exchange Rates and International Macroeconomics. University of Chicago, Chicago.

Menkhoff, L., Sarno, L., Schmeling, M., Schrimpf, A., 2012. Carry trades and global foreign exchange volatility. Journal of Finance 67, 681-718.

Molodtsova, T., Papell, D. H., 2009. Out-of-sample exchange rate predictability with taylor rule fundamentals. Journal of International Economics 77, 167-180.

Newey, W. K., West, K. D., 1987. A simple, positive semi-definite, heteroskedasticity and autocorrelation consistent covariance matrix. Econometrica 55, 703-708.

Nucera, F., Valente, G., 2013. Carry trades and the performance of currency hedge funds. Journal of International Money and Finance 33, 407-425.

Pastor, L., Stambaugh, R., 2003. Liquidity risk and expected stock returns. Journal of Political Economy 111, 642-685.

Pesaran, H. M., Timmermann, A., 2005. Small sample properties of forecasts from autoregressive models under structural breaks. Journal of Econometrics 129, 183-217. 
Rime, D., Sarno, L., Sojli, E., 2010. Exchange rate forecasting, order flow and macroeconomic information. Journal of International Economics 80, 72-88.

Ross, S. A., 1976. The arbitrage theory of capital asset pricing. Journal of Economic Theory $13,341-360$.

Rossi, B., 2013. Exchange rate predictability. Journal of Economic Literature 51, 1063-1119.

Sharpe, W. F., 1964. Capital asset prices: A theory of market equilibrium under conditions of risk. Journal of Finance 19, 425-442.

Simin, T., 2008. The poor predictive performance of asset pricing models. Journal of Financial and Quantitative Analysis 43, 355-380.

Taylor, A. M., Taylor, M. P., 2004. The purchasing power parity debate. Journal of Economic Perspectives 18, 135-158.

Taylor, J. B., 1993. Discretion versus policy rules in practice. Carnegie-Rochester Conference Series on Public Policy 39, 195-214.

Theil, H., 1996. Applied Economic Forecasting. North Holland.

Thornton, D. L., Valente, G., 2012. Out-of-sample predictions of bond excess returns and forward rates: An asset allocation perspective. Review of Financial Studies 25, 3141-3168.

Van Binsbergen, J. H., Koijen, R. S. J., 2010. Predictive regression: A present value approach. Journal of Finance 65, 1439-1471.

Verdelhan, A., 2013. The share of systematic variation in bilateral exchange rates, Working Paper, MIT Sloan School of Management.

Welch, I., Goyal, A., 2008. A comprehensive look at the empirical performance of equity premium prediction. Review of Financial Studies 21, 1455-1508.

West, K. D., 1996. Asymptotic inference about predictive ability. Econometrica 64, 1067-1084.

West, K. D., Edison, H. J., Cho, D., 1993. A utility-based comparison of some models of exchange rate volatility. Journal of International Economics 35, 23-45. 
Table 1

\section{Data Sources and Descriptive Statistics}

The table provides a brief description and summary statistics of exchange rates for the US relative to eight developed (panel A) and eight developing (panel B) countries. The exchange rates expressed as units of USD per foreign currency unit are closing midpoint quotes (average of bid and ask quotes) for daily spot and one-month forward exchange rates on the last trading day of each month, retrieved from Barclays Bank International (BBI) and World Markets PLC/Reuters (WMR) available on the Datastream. The sample period is from November 1983 to November 2013.

\begin{tabular}{|c|c|c|c|c|c|c|c|c|c|c|c|}
\hline \multirow[b]{2}{*}{ Country } & \multicolumn{3}{|c|}{ Sample } & \multicolumn{4}{|c|}{ Spot Exchange Rate } & \multicolumn{4}{|c|}{ One-Month Forward Exchange Rate } \\
\hline & Source & Start & End & Mean & Stdev & Min & Max & Mean & Stdev & Min & $\operatorname{Max}$ \\
\hline \multicolumn{12}{|c|}{ Panel A: Developed Countries } \\
\hline Australia & BBI & 1984:12 & 2013:11 & 0.755 & 0.131 & 0.488 & 1.099 & 0.753 & 0.131 & 0.488 & 1.095 \\
\hline Canada & $\mathrm{BBI}$ & $1983: 11$ & 2013:11 & 0.803 & 0.111 & 0.623 & 1.053 & 0.803 & 0.111 & 0.623 & 1.052 \\
\hline Germany $\backslash$ Euro Area & BBI & 1983:11 & 2013:11 & 0.592 & 0.105 & 0.299 & 0.808 & 0.592 & 0.105 & 0.302 & 0.807 \\
\hline Japan & BBI & $1983: 11$ & 2013:11 & 0.009 & 0.002 & 0.004 & 0.013 & 0.009 & 0.002 & 0.004 & 0.013 \\
\hline New Zealand & BBI & 1984:12 & 2013:11 & 0.619 & 0.109 & 0.398 & 0.877 & 0.617 & 0.109 & 0.398 & 0.875 \\
\hline Sweden & BBI & 1983:11 & 2013:11 & 0.139 & 0.020 & 0.092 & 0.194 & 0.138 & 0.020 & 0.092 & 0.192 \\
\hline Switzerland & $\mathrm{BBI}$ & $1983: 11$ & 2013:11 & 0.750 & 0.174 & 0.351 & 1.270 & 0.751 & 0.174 & 0.354 & 1.271 \\
\hline United Kingdom & WMR & $1983: 11$ & $2013: 11$ & 1.631 & 0.174 & 1.082 & 2.079 & 1.628 & 0.173 & 1.077 & 2.077 \\
\hline
\end{tabular}

Panel B: Developing Countries

$\begin{array}{llllllllllll}\text { Czech Republic } & \text { WMR } & 1996: 12 & 2013: 11 & 0.042 & 0.011 & 0.024 & 0.066 & 0.042 & 0.011 & 0.024 & 0.066 \\ \text { Hungary } & \text { WMR } & 1997: 10 & 2013: 11 & 0.005 & 0.001 & 0.003 & 0.007 & 0.005 & 0.001 & 0.003 & 0.007 \\ \text { India } & \text { WMR } & 1997: 10 & 2013: 11 & 0.022 & 0.002 & 0.015 & 0.027 & 0.022 & 0.002 & 0.015 & 0.027 \\ \text { Philippines } & \text { WMR } & 1996: 12 & 2013: 11 & 0.022 & 0.004 & 0.018 & 0.038 & 0.022 & 0.004 & 0.018 & 0.038 \\ \text { Singapore } & \text { BBI } & 1984: 12 & 2013: 11 & 0.620 & 0.097 & 0.442 & 0.831 & 0.621 & 0.097 & 0.443 & 0.831 \\ \text { South Africa } & \text { BBI } & 1983: 11 & 2013: 11 & 0.253 & 0.154 & 0.084 & 0.835 & 0.251 & 0.153 & 0.082 & 0.826 \\ \text { Taiwan } & \text { WMR } & 1996: 12 & 2013: 11 & 0.031 & 0.002 & 0.028 & 0.036 & 0.031 & 0.002 & 0.028 & 0.036 \\ \text { Thailand } & \text { WMR } & 1996: 12 & 2013: 11 & 0.028 & 0.004 & 0.019 & 0.040 & 0.028 & 0.004 & 0.019 & 0.039 \\ & & & & & & & & & & & \end{array}$


Table 2

\section{Forecasts Based on Unconditional Expectations of Factors: The Rolling Scheme}

The table presents statistical measures of out-of-sample forecast accuracy of linear factor models for exchange rate returns relative to a random walk with drift (RWD) benchmark (equation (2)). The one-month ahead forecasts of exchange rate returns for individual currencies are from rolling regressions with a eight-year window using unconditional expectations of risk factors. Panels A and B report results for currencies from eight developed and eight developing countries, respectively. For each currency $k$ and competing model in equation $(i)$ $(i=6,7, \ldots, 15)$, DMW denotes the Diebold and Mariano (1995) and West (1996) MSFE ${ }_{i}^{k}$ - $t$ statistic based on the Newey and West (1987) estimator, which tests the null hypothesis of equal mean squared forecast error (MSFE) between the RWD and the competing model. RC denotes $\max _{i=6,7, \ldots, 15} \mathrm{MSFE}_{i}^{k}-t$ statistic for reality check (best model) following Clark and McCracken (2012), which tests the joint null hypothesis of no predictive ability across all competing models. One-sided (to the right) critical values are obtained using 10,000 fixed regressor bootstrap replications as in Clark and McCracken (2012). $a$ and $b$ denote statistical significance at the $5 \%$ and $10 \%$ levels, respectively. GW denotes the Giacomini and White (2006) $p_{i}^{k}$-value for pairwise test of equal conditional predictive ability. Numbers in parentheses show the proportion of times the competing model outperforms the RWD over the out-of-sample period. $*(\dagger)$ indicates that the GW test rejects the null hypothesis of equal conditional predictive ability at the $10 \%$ significance level and that the competing model outperforms (is outperformed by) the RWD more than $50 \%$ of the time. The out-of-sample forecasts are from November 1991 to November 2013.

\begin{tabular}{|c|c|c|c|c|c|c|c|c|c|c|c|}
\hline & \multicolumn{10}{|c|}{ Model } & \multirow[b]{2}{*}{$\mathrm{RC}$} \\
\hline & 6 & 7 & 8 & 9 & 10 & 11 & 12 & 13 & 14 & 15 & \\
\hline \multicolumn{12}{|c|}{ Panel A: Developed Countries } \\
\hline \multicolumn{12}{|c|}{ Australia } \\
\hline DMW & $1.21^{b}$ & 0.51 & 0.62 & -1.08 & -0.92 & -1.01 & -0.91 & -0.61 & -1.11 & -0.94 & 1.21 \\
\hline GW & 0.13 & 0.27 & 0.39 & 0.21 & 0.22 & 0.24 & 0.30 & 0.23 & 0.32 & 0.26 & \\
\hline & $(0.83)$ & $(0.74)$ & $(0.82)$ & $(0.10)$ & $(0.11)$ & $(0.10)$ & $(0.10)$ & $(0.21)$ & $(0.08)$ & $(0.12)$ & \\
\hline \multicolumn{12}{|c|}{ Canada } \\
\hline DMW & 0.19 & -0.48 & -0.86 & -0.41 & -0.50 & -0.23 & -0.37 & -0.47 & -0.52 & -0.62 & 0.19 \\
\hline GW & $0.00^{*}$ & 0.29 & 0.53 & 0.93 & 0.89 & 0.98 & 0.94 & 0.89 & 0.85 & 0.72 & \\
\hline & $(0.68)$ & $(0.17)$ & $(0.11)$ & $(0.00)$ & $(0.00)$ & $(0.00)$ & $(0.00)$ & $(0.00)$ & $(0.01)$ & $(0.04)$ & \\
\hline \multicolumn{12}{|c|}{ Germany $\backslash$ Euro Area } \\
\hline DMW & -1.60 & -1.99 & -1.51 & -2.04 & -1.72 & -2.11 & -2.29 & -2.43 & -2.33 & -2.46 & -1.51 \\
\hline GW & $0.00^{\dagger}$ & $0.00^{\dagger}$ & $0.00^{\dagger}$ & 0.21 & 0.13 & 0.19 & $0.03^{\dagger}$ & $0.01^{\dagger}$ & $0.04^{\dagger}$ & $0.01^{\dagger}$ & \\
\hline & $(0.16)$ & $(0.17)$ & $(0.19)$ & $(0.00)$ & $(0.05)$ & $(0.00)$ & $(0.03)$ & $(0.05)$ & $(0.02)$ & $(0.03)$ & \\
\hline \multicolumn{12}{|c|}{ Japan } \\
\hline DMW & -1.51 & -1.03 & -0.63 & -0.95 & $-0.12^{b}$ & -1.03 & -1.18 & -0.52 & -1.65 & -0.98 & -0.12 \\
\hline GW & $0.02^{\dagger}$ & 0.56 & 0.34 & 0.66 & 0.88 & 0.47 & 0.58 & 0.72 & 0.11 & 0.31 & \\
\hline & $(0.11)$ & $(0.01)$ & $(0.16)$ & $(0.00)$ & $(0.28)$ & $(0.01)$ & $(0.00)$ & $(0.09)$ & $(0.02)$ & $(0.09)$ & \\
\hline \multicolumn{12}{|c|}{ New Zealand } \\
\hline DMW & 0.17 & 0.14 & -0.44 & -0.49 & -0.37 & -0.68 & -0.40 & $0.83^{a}$ & $1.13^{a}$ & $1.23^{a}$ & 1.23 \\
\hline GW & 0.97 & 0.73 & 0.86 & 0.56 & 0.69 & 0.49 & 0.67 & 0.51 & 0.37 & 0.37 & \\
\hline & $(0.98)$ & $(0.80)$ & $(0.03)$ & $(0.11)$ & $(0.10)$ & $(0.09)$ & $(0.11)$ & $(0.95)$ & $(0.94)$ & $(0.98)$ & \\
\hline \multicolumn{12}{|c|}{ Sweden } \\
\hline DMW & -0.80 & -0.80 & -0.77 & -1.53 & -1.23 & -1.54 & -1.46 & -2.16 & -1.36 & -2.00 & -0.77 \\
\hline GW & $0.00^{\dagger}$ & $0.00^{\dagger}$ & $0.00^{\dagger}$ & $0.09^{\dagger}$ & 0.23 & $0.08^{\dagger}$ & 0.30 & $0.06^{\dagger}$ & 0.31 & $0.05^{\dagger}$ & \\
\hline & $(0.40)$ & $(0.33)$ & $(0.38)$ & $(0.04)$ & $(0.03)$ & $(0.04)$ & $(0.00)$ & $(0.01)$ & $(0.01)$ & $(0.03)$ & \\
\hline \multicolumn{12}{|c|}{ Switzerland } \\
\hline DMW & -1.78 & -1.68 & -1.86 & -1.60 & -2.02 & -1.86 & -1.89 & -2.14 & -1.91 & -1.95 & -1.60 \\
\hline GW & $0.00^{\dagger}$ & 0.13 & $0.00^{\dagger}$ & $0.00^{\dagger}$ & $0.00^{\dagger}$ & $0.00^{\dagger}$ & $0.00^{\dagger}$ & $0.00^{\dagger}$ & $0.00^{\dagger}$ & $0.00^{\dagger}$ & \\
\hline & $(0.17)$ & $(0.06)$ & $(0.15)$ & $(0.15)$ & $(0.13)$ & $(0.16)$ & $(0.16)$ & $(0.14)$ & $(0.17)$ & $(0.14)$ & \\
\hline \multicolumn{12}{|c|}{ United Kingdom } \\
\hline DMW & 0.16 & -0.20 & -0.45 & -1.05 & -1.05 & -1.07 & -1.05 & -1.14 & -0.99 & -1.06 & 0.16 \\
\hline GW & 0.86 & 0.94 & 0.95 & 0.31 & 0.28 & 0.31 & 0.23 & 0.29 & 0.46 & 0.44 & \\
\hline & $(0.91)$ & $(0.23)$ & $(0.08)$ & $(0.06)$ & $(0.08)$ & $(0.06)$ & $(0.09)$ & $(0.06)$ & $(0.05)$ & $(0.02)$ & \\
\hline
\end{tabular}


Table $\mathbf{2}$ - Continued

\begin{tabular}{|c|c|c|c|c|c|c|c|c|c|c|c|}
\hline & \multicolumn{10}{|c|}{ Model } & \multirow[b]{2}{*}{$\mathrm{RC}$} \\
\hline & 6 & 7 & 8 & 9 & 10 & 11 & 12 & 13 & 14 & 15 & \\
\hline \multicolumn{12}{|c|}{ Panel B: Developing Countries } \\
\hline \multicolumn{12}{|c|}{ Czech Republic } \\
\hline DMW & -0.95 & 0.23 & -0.33 & $0.61^{b}$ & 0.32 & $0.58^{b}$ & $0.61^{b}$ & 0.18 & 0.49 & -0.08 & 0.61 \\
\hline GW & 0.71 & 0.94 & 0.94 & 0.66 & 0.63 & 0.67 & 0.65 & 0.63 & 0.65 & 0.76 & \\
\hline & $(0.02)$ & $(0.85)$ & $(0.01)$ & $(0.80)$ & $(0.61)$ & $(0.80)$ & $(0.81)$ & $(0.57)$ & $(0.78)$ & $(0.36)$ & \\
\hline \multicolumn{12}{|c|}{ Hungary } \\
\hline DMW & -1.00 & -1.35 & -1.32 & -0.89 & -1.54 & -1.20 & -0.67 & -1.85 & -1.20 & -1.48 & -0.67 \\
\hline \multirow[t]{2}{*}{ GW } & 0.36 & $0.01^{\dagger}$ & 0.35 & 0.68 & 0.32 & 0.46 & 0.62 & $0.03^{\dagger}$ & 0.65 & $0.02^{\dagger}$ & \\
\hline & $(0.17)$ & $(0.17)$ & $(0.06)$ & $(0.02)$ & $(0.02)$ & $(0.04)$ & $(0.23)$ & $(0.18)$ & $(0.05)$ & $(0.23)$ & \\
\hline \multicolumn{12}{|c|}{ India } \\
\hline DMW & -1.05 & -0.34 & -0.75 & -2.27 & -2.07 & -2.36 & -2.47 & -1.98 & -2.46 & -1.84 & -0.34 \\
\hline GW & 0.17 & 0.42 & 0.42 & $0.01^{\dagger}$ & $0.01^{\dagger}$ & $0.01^{\dagger}$ & $0.00^{\dagger}$ & $0.00^{\dagger}$ & $0.00^{\dagger}$ & $0.00^{\dagger}$ & \\
\hline & $(0.15)$ & $(0.19)$ & $(0.11)$ & $(0.15)$ & $(0.14)$ & $(0.13)$ & $(0.16)$ & $(0.15)$ & $(0.14)$ & $(0.15)$ & \\
\hline \multicolumn{12}{|c|}{ Philippines } \\
\hline DMW & -1.17 & -1.85 & -1.22 & -2.57 & -2.53 & -2.63 & -2.66 & -2.94 & -2.80 & -3.05 & -1.17 \\
\hline GW & 0.37 & $0.00^{\dagger}$ & 0.28 & $0.00^{\dagger}$ & $0.00^{\dagger}$ & $0.00^{\dagger}$ & $0.00^{\dagger}$ & $0.00^{\dagger}$ & $0.00^{\dagger}$ & $0.00^{\dagger}$ & \\
\hline & $(0.00)$ & $(0.23)$ & $(0.00)$ & $(0.07)$ & $(0.07)$ & $(0.07)$ & $(0.08)$ & $(0.06)$ & $(0.07)$ & $(0.04)$ & \\
\hline \multicolumn{12}{|c|}{ Singapore } \\
\hline DMW & -0.51 & 0.85 & -0.16 & -0.51 & -0.61 & -0.46 & $0.40^{a}$ & $0.08^{b}$ & $0.29^{a}$ & $0.15^{b}$ & 0.85 \\
\hline GW & 0.83 & 0.49 & 0.72 & 0.64 & 0.86 & 0.59 & $0.09 *$ & 0.34 & 0.17 & 0.26 & \\
\hline & $(0.01)$ & $(0.96)$ & $(0.25)$ & $(0.09)$ & $(0.00)$ & $(0.11)$ & $(0.75)$ & $(0.57)$ & $(0.73)$ & $(0.64)$ & \\
\hline \multicolumn{12}{|c|}{ South Africa } \\
\hline DMW & -1.97 & $1.01^{b}$ & -1.83 & $-0.01^{a}$ & -2.01 & $-0.17^{a}$ & -1.34 & -2.14 & $-0.05^{a}$ & -2.12 & 1.01 \\
\hline GW & $0.01^{\dagger}$ & 0.41 & $0.01^{\dagger}$ & $0.00^{\dagger}$ & 0.14 & $0.00^{\dagger}$ & 0.37 & $0.00^{\dagger}$ & 0.10 & $0.00^{\dagger}$ & \\
\hline & $(0.06)$ & $(0.98)$ & $(0.08)$ & $(0.49)$ & $(0.02)$ & $(0.33)$ & $(0.00)$ & $(0.02)$ & $(0.38)$ & $(0.02)$ & \\
\hline \multicolumn{12}{|c|}{ Taiwan } \\
\hline DMW & $1.69^{a}$ & -1.22 & $1.54^{a}$ & $0.34^{b}$ & $0.55^{b}$ & 0.21 & $0.37^{b}$ & $0.60^{a}$ & $0.32^{b}$ & $0.54^{a}$ & $1.69^{b}$ \\
\hline GW & 0.18 & 0.28 & $0.02^{*}$ & $0.01^{*}$ & $0.01^{*}$ & $0.01^{*}$ & $0.01^{*}$ & $0.00^{*}$ & $0.01^{*}$ & $0.02 *$ & \\
\hline & $(0.99)$ & $(0.03)$ & $(0.91)$ & $(0.75)$ & $(0.79)$ & $(0.69)$ & $(0.75)$ & $(0.79)$ & $(0.74)$ & $(0.78)$ & \\
\hline \multicolumn{12}{|c|}{ Thailand } \\
\hline DMW & -0.20 & 0.43 & -0.14 & -1.20 & -1.20 & -1.18 & -0.76 & -0.61 & -0.88 & -0.72 & 0.43 \\
\hline GW & 0.95 & $0.04^{*}$ & 0.96 & 0.57 & 0.57 & 0.57 & 0.74 & 0.78 & 0.65 & 0.74 & \\
\hline & $(0.07)$ & $(0.74)$ & $(0.08)$ & $(0.01)$ & $(0.01)$ & $(0.01)$ & $(0.04)$ & $(0.05)$ & $(0.05)$ & $(0.04)$ & \\
\hline
\end{tabular}


Table 3

Forecasts Based on Unconditional Expectations of Factors: The Recursive Scheme

The table presents the Diebold and Mariano (1995) and West (1996) $\mathrm{MSFE}_{i}^{k}-t$ statistics for currency $k$ based on the Newey and West (1987) estimator, which test the null hypothesis of equal mean squared forecast error (MSFE) between the random walk with drift benchmark (equation (2)) and the competing model in equation (i) $(i=6,7, \ldots, 15)$. The one-month ahead forecasts of exchange rate returns for individual currencies are from recursive regressions with a eight-year starting expanding window using unconditional expectations of risk factors. See also notes to Table 2 .

\begin{tabular}{|c|c|c|c|c|c|c|c|c|c|c|c|}
\hline \multirow[b]{2}{*}{ Country } & \multicolumn{10}{|c|}{ Model } & \multirow[b]{2}{*}{$\mathrm{RC}$} \\
\hline & 6 & 7 & 8 & 9 & 10 & 11 & 12 & 13 & 14 & 15 & \\
\hline \multicolumn{12}{|c|}{ Panel A: Developed Countries } \\
\hline Australia & 0.62 & -0.52 & 0.40 & -1.18 & -1.06 & -1.16 & -1.23 & -2.40 & -1.37 & -2.42 & 0.62 \\
\hline Canada & 0.44 & 0.61 & 0.53 & -0.25 & -0.23 & -0.23 & 0.10 & 0.16 & 0.03 & 0.08 & 0.61 \\
\hline Germany $\backslash$ Euro Area & -0.29 & -0.70 & -0.30 & -0.92 & -1.08 & -0.90 & -0.81 & -0.97 & -0.82 & -0.98 & -0.29 \\
\hline Japan & -2.47 & -2.43 & -1.92 & -0.13 & $0.18^{b}$ & -0.27 & -0.32 & -0.06 & -0.58 & -0.55 & 0.18 \\
\hline New Zealand & 0.18 & -0.67 & 0.09 & -0.49 & -0.54 & -0.46 & -0.82 & -0.64 & -0.85 & -0.77 & 0.18 \\
\hline Sweden & -0.41 & -0.35 & -0.37 & -1.37 & -1.37 & -1.37 & -1.53 & -1.76 & -1.63 & -1.80 & -0.35 \\
\hline Switzerland & 0.29 & 0.54 & 0.21 & -1.32 & -1.67 & -1.30 & -1.15 & -1.43 & -1.09 & -1.39 & 0.54 \\
\hline United Kingdom & -0.20 & -0.07 & -0.20 & -0.98 & -1.07 & -0.97 & -0.87 & -0.90 & -0.74 & -0.81 & -0.07 \\
\hline \multicolumn{12}{|c|}{ Panel B: Developing Countries } \\
\hline Czech Republic & 0.42 & 0.21 & 0.50 & -0.24 & -0.10 & -0.20 & 0.18 & 0.27 & 0.92 & 1.20 & 1.20 \\
\hline Hungary & -0.30 & -0.51 & -0.33 & -1.30 & -1.63 & -1.43 & -0.77 & -0.87 & -0.84 & -0.82 & -0.30 \\
\hline India & -0.27 & -0.20 & 0.50 & -1.08 & -1.12 & -0.95 & -0.57 & -0.44 & -0.21 & -0.05 & 0.50 \\
\hline Philippines & -1.32 & -2.90 & -1.53 & $1.05^{b}$ & $0.91^{b}$ & $1.01^{b}$ & $1.02^{b}$ & -0.35 & $1.03^{b}$ & -0.31 & 1.05 \\
\hline Singapore & $1.63^{a}$ & $1.62^{a}$ & $1.65^{a}$ & -0.32 & -0.36 & -0.34 & $0.22^{b}$ & $0.20^{b}$ & $0.11^{b}$ & $0.16^{b}$ & $1.65^{b}$ \\
\hline South Africa & 0.30 & $1.79^{a}$ & 0.31 & -1.98 & -2.07 & -1.97 & $0.93^{a}$ & -2.02 & $0.79^{a}$ & -1.97 & $1.79^{b}$ \\
\hline Taiwan & 0.71 & -2.09 & 0.58 & $0.96^{a}$ & $0.97^{b}$ & $0.93^{b}$ & $0.81^{b}$ & $0.81^{b}$ & $0.77^{b}$ & $0.74^{b}$ & 0.97 \\
\hline Thailand & 1.55 & 0.94 & 1.52 & 0.34 & 0.40 & 0.39 & $1.72^{b}$ & $1.83^{b}$ & $1.72^{b}$ & $1.91^{b}$ & 1.91 \\
\hline
\end{tabular}


Table 4

\section{Forecasts Based on Conditional Expectations of Factors: The Rolling Scheme}

The table presents statistical measures of out-of-sample forecast accuracy of linear factor models for exchange rate returns relative to a random walk with drift benchmark (equation (2)). The one-month ahead forecasts of exchange rate returns for individual currencies are from rolling regressions with a eight-year window using conditional expectations of risk factors. RC denotes $\underset{i=3,4, \ldots, 15}{\max } \mathrm{MSE}_{i}^{k}$ - $t$ statistic for reality check (best model) following Clark and McCracken (2012), which tests the joint null hypothesis of no predictive ability across all competing models. See also notes to Table 2.

\begin{tabular}{|c|c|c|c|c|c|c|c|c|c|c|c|c|c|c|}
\hline & \multicolumn{14}{|c|}{ Model } \\
\hline & 3 & 4 & 5 & 6 & 7 & 8 & 9 & 10 & 11 & 12 & 13 & 14 & 15 & $\mathrm{RC}$ \\
\hline & & & & & & nel A: I & Developed & Countri & & & & & & \\
\hline & & & & & & & Australia & & & & & & & \\
\hline DMW & -0.73 & -1.01 & -0.79 & -0.26 & -0.25 & -0.50 & -1.24 & -1.24 & -1.24 & -0.95 & -0.61 & -1.20 & -0.98 & -0.25 \\
\hline GW & $\begin{array}{c}0.02^{\dagger} \\
(0.22)\end{array}$ & $\begin{array}{c}0.04^{\dagger} \\
(0.17)\end{array}$ & $\begin{array}{c}0.00^{\dagger} \\
(0.23)\end{array}$ & $\begin{array}{c}0.01^{\dagger} \\
(0.38)\end{array}$ & $\begin{array}{c}0.02^{\dagger} \\
(0.40)\end{array}$ & $\begin{array}{c}0.00^{\dagger} \\
(0.34)\end{array}$ & $\begin{array}{r}0.47 \\
(0.02)\end{array}$ & $\begin{array}{r}0.47 \\
(0.02)\end{array}$ & $\begin{array}{r}0.47 \\
(0.02)\end{array}$ & $\begin{array}{r}0.50 \\
(0.07)\end{array}$ & $\begin{array}{r}0.49 \\
(0.12)\end{array}$ & $\begin{array}{r}0.38 \\
(0.06)\end{array}$ & $\begin{array}{r}0.35 \\
(0.10)\end{array}$ & \\
\hline & & & & & & & Canada & & & & & & & \\
\hline DMW & -0.30 & -0.28 & -0.54 & -0.33 & -0.48 & -0.63 & -0.82 & -0.82 & -0.82 & -0.79 & -0.87 & -0.90 & -0.86 & -0.28 \\
\hline GW & $\begin{array}{r}0.93 \\
(0.06)\end{array}$ & $\begin{array}{r}0.88 \\
(0.11)\end{array}$ & $\begin{array}{r}0.78 \\
(0.07)\end{array}$ & $\begin{array}{r}0.95 \\
(0.00)\end{array}$ & $\begin{array}{r}0.89 \\
(0.01)\end{array}$ & $\begin{array}{r}0.74 \\
(0.05)\end{array}$ & $\begin{array}{r}0.74 \\
(0.02)\end{array}$ & $\begin{array}{r}0.74 \\
(0.02)\end{array}$ & $\begin{array}{r}0.74 \\
(0.02)\end{array}$ & $\begin{array}{r}0.72 \\
(0.00)\end{array}$ & $\begin{array}{r}0.72 \\
(0.00)\end{array}$ & $\begin{array}{r}0.71 \\
(0.00)\end{array}$ & $\begin{array}{r}0.72 \\
(0.00)\end{array}$ & \\
\hline & & & & & & Germ & any $\backslash$ Eurc & Area & & & & & & \\
\hline DMW & 0.29 & 0.31 & 0.36 & 0.18 & 0.10 & 0.29 & -0.20 & -0.20 & -0.20 & -0.23 & -0.21 & -0.19 & -0.23 & 0.36 \\
\hline GW & $\begin{array}{r}0.80 \\
(0.68)\end{array}$ & $\begin{array}{r}0.52 \\
(0.67)\end{array}$ & $\begin{array}{r}0.79 \\
(0.75)\end{array}$ & $\begin{array}{r}0.96 \\
(0.19)\end{array}$ & $\begin{array}{r}0.94 \\
(0.12)\end{array}$ & $\begin{array}{r}0.99 \\
(0.68)\end{array}$ & $\begin{array}{c}0.01^{\dagger} \\
(0.40)\end{array}$ & $\begin{array}{c}0.01^{\dagger} \\
(0.40)\end{array}$ & $\begin{array}{c}0.01^{\dagger} \\
(0.40)\end{array}$ & $\begin{array}{r}0.02^{\dagger} \\
(0.35)\end{array}$ & $\begin{array}{r}0.13 \\
(0.32)\end{array}$ & $\begin{array}{c}0.04^{\dagger} \\
(0.35)\end{array}$ & $\begin{array}{r}0.25 \\
(0.27)\end{array}$ & \\
\hline & & & & & & & Japan & & & & & & & \\
\hline DMW & -1.07 & -1.07 & -0.91 & -0.26 & -1.07 & 0.45 & -1.08 & -1.08 & -1.08 & -1.07 & -1.07 & -1.32 & -1.10 & 0.45 \\
\hline GW & $\begin{array}{c}0.07^{\dagger} \\
(0.06)\end{array}$ & $\begin{array}{r}0.11 \\
(0.03)\end{array}$ & $\begin{array}{r}0.28 \\
(0.03)\end{array}$ & $\begin{array}{r}0.43 \\
(0.16)\end{array}$ & $\begin{array}{r}0.55 \\
(0.00)\end{array}$ & $\begin{array}{r}0.11 \\
(0.71)\end{array}$ & $\begin{array}{r}0.40 \\
(0.00)\end{array}$ & $\begin{array}{r}0.40 \\
(0.00)\end{array}$ & $\begin{array}{r}0.40 \\
(0.00)\end{array}$ & $\begin{array}{c}0.01^{\dagger} \\
(0.12)\end{array}$ & $\begin{array}{r}0.57 \\
(0.00)\end{array}$ & $\begin{array}{c}0.00^{\dagger} \\
(0.18)\end{array}$ & $\begin{array}{r}0.50 \\
(0.00)\end{array}$ & \\
\hline & & & & & & & ew Zeala & & & & & & & \\
\hline DMW & -0.90 & -1.01 & -0.76 & -0.55 & -0.63 & -0.78 & -1.32 & -1.32 & -1.32 & -1.06 & -0.11 & -0.11 & 0.25 & 0.25 \\
\hline GW & $\begin{array}{c}0.01^{\dagger} \\
(0.22)\end{array}$ & $\begin{array}{c}0.01^{\dagger} \\
(0.20)\end{array}$ & $\begin{array}{c}0.01^{\dagger} \\
(0.23)\end{array}$ & $\begin{array}{c}0.01^{\dagger} \\
(0.28)\end{array}$ & $\begin{array}{r}0.56 \\
(0.08)\end{array}$ & $\begin{array}{c}0.01^{\dagger} \\
(0.22)\end{array}$ & $\begin{array}{r}0.36 \\
(0.02)\end{array}$ & $\begin{array}{r}0.36 \\
(0.02)\end{array}$ & $\begin{array}{r}0.36 \\
(0.02)\end{array}$ & $\begin{array}{r}0.45 \\
(0.05)\end{array}$ & $\begin{array}{r}0.81 \\
(0.27)\end{array}$ & $\begin{array}{r}0.87 \\
(0.30)\end{array}$ & $\begin{array}{r}0.79 \\
(0.78)\end{array}$ & \\
\hline & & & & & & & Sweden & & & & & & & \\
\hline DMW & -0.58 & -0.88 & -0.57 & -0.25 & -1.08 & -0.20 & -1.34 & -1.34 & -1.34 & -0.73 & -1.08 & -0.67 & -1.06 & -0.20 \\
\hline GW & $\begin{array}{r}0.27 \\
(0.20)\end{array}$ & $\begin{array}{c}0.06^{\dagger} \\
(0.19)\end{array}$ & $\begin{array}{r}0.26 \\
(0.20)\end{array}$ & $\begin{array}{r}0.45 \\
(0.24)\end{array}$ & $\begin{array}{r}0.48 \\
(0.00)\end{array}$ & $\begin{array}{r}0.46 \\
(0.26)\end{array}$ & $\begin{array}{c}0.03^{\dagger} \\
(0.13)\end{array}$ & $\begin{array}{c}0.03^{\dagger} \\
(0.13)\end{array}$ & $\begin{array}{c}0.03^{\dagger} \\
(0.13)\end{array}$ & $\begin{array}{r}0.29 \\
(0.14)\end{array}$ & $\begin{array}{r}0.52 \\
(0.00)\end{array}$ & $\begin{array}{r}0.23 \\
(0.18)\end{array}$ & $\begin{array}{r}0.54 \\
(0.00)\end{array}$ & \\
\hline & & & & & & & witzerlan & & & & & & & \\
\hline DMW & 0.27 & 0.69 & 0.43 & -0.27 & 0.35 & -0.36 & -0.08 & -0.08 & -0.08 & -0.03 & 0.41 & -0.32 & 0.44 & 0.69 \\
\hline GW & $\begin{array}{r}0.80 \\
(0.64)\end{array}$ & $\begin{array}{r}0.84 \\
(0.93)\end{array}$ & $\begin{array}{r}0.90 \\
(0.81)\end{array}$ & $\begin{array}{r}0.62 \\
(0.17)\end{array}$ & $\begin{array}{r}0.90 \\
(0.74)\end{array}$ & $\begin{array}{r}0.82 \\
(0.02)\end{array}$ & $\begin{array}{r}0.81 \\
(0.27)\end{array}$ & $\begin{array}{r}0.81 \\
(0.27)\end{array}$ & $\begin{array}{r}0.81 \\
(0.27)\end{array}$ & $\begin{array}{r}0.91 \\
(0.18)\end{array}$ & $\begin{array}{r}0.94 \\
(0.94)\end{array}$ & $\begin{array}{r}0.87 \\
(0.06)\end{array}$ & $\begin{array}{r}0.94 \\
(1.00)\end{array}$ & \\
\hline & & & & & & Uni & ted King & dom & & & & & & \\
\hline DMW & -0.81 & -0.85 & -0.75 & -1.36 & -0.93 & -1.10 & -1.50 & -1.50 & -1.50 & -1.78 & -1.66 & -1.63 & -1.54 & -0.75 \\
\hline GW & $\begin{array}{r}0.43 \\
(0.05)\end{array}$ & $\begin{array}{r}0.32 \\
(0.07)\end{array}$ & $\begin{array}{r}0.52 \\
(0.04)\end{array}$ & $\begin{array}{r}0.11 \\
(0.05)\end{array}$ & $\begin{array}{c}0.09^{\dagger} \\
(0.13)\end{array}$ & $\begin{array}{r}0.21 \\
(0.06)\end{array}$ & $\begin{array}{r}0.10 \\
(0.05)\end{array}$ & $\begin{array}{r}0.10 \\
(0.05)\end{array}$ & $\begin{array}{r}0.10 \\
(0.05)\end{array}$ & $\begin{array}{c}0.02^{\dagger} \\
(0.05)\end{array}$ & $\begin{array}{c}0.04^{\dagger} \\
(0.08)\end{array}$ & $\begin{array}{c}0.06^{\dagger} \\
(0.05)\end{array}$ & $\begin{array}{c}0.08^{\dagger} \\
(0.06)\end{array}$ & \\
\hline
\end{tabular}


Table 4 - Continued

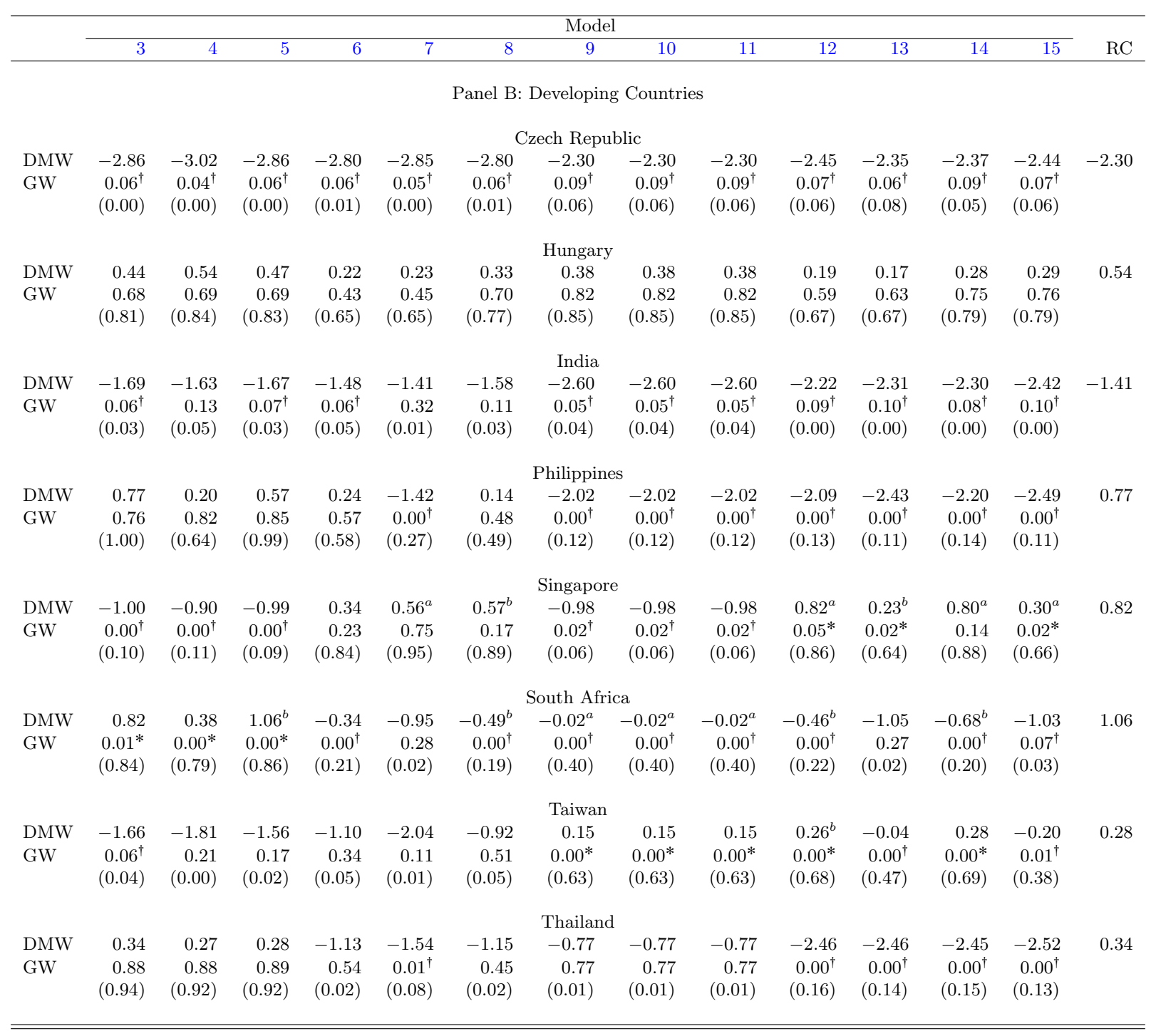


Table 5

Forecasts Based on Conditional Expectations of Factors: The Recursive Scheme

The table presents the Diebold and Mariano (1995) and West (1996) MSFE ${ }_{i}^{k}-t$ statistics for currency $k$ based on the Newey and West (1987) estimator, which test the null hypothesis of equal mean squared forecast error (MSFE) between the random walk with drift benchmark (equation (2)) and the competing model in equation ( $i$ ) $(i=3,4, \ldots, 15)$. The one-month ahead forecasts of exchange rate returns for individual currencies are from recursive regressions with a eight-year starting expanding window using conditional expectations of risk factors. RC denotes $\underset{i=3,4, \ldots, 15}{\max } \mathrm{MSE}_{i}^{k}$ - $t$ statistic for reality check (best model) following Clark and McCracken (2012), which tests the joint null hypothesis of no predictive ability across all competing models. See also notes to Table 2 .

\begin{tabular}{|c|c|c|c|c|c|c|c|c|c|c|c|c|c|c|}
\hline \multirow[b]{2}{*}{ Country } & \multicolumn{14}{|c|}{ Model } \\
\hline & 3 & 4 & 5 & 6 & 7 & 8 & 9 & 10 & 11 & 12 & 13 & 14 & 15 & $\mathrm{RC}$ \\
\hline \multicolumn{15}{|c|}{ Panel A: Developed Countries } \\
\hline Australia & -0.65 & -0.86 & -0.69 & -0.68 & -1.19 & -0.84 & -1.37 & -1.37 & -1.37 & -1.53 & -2.31 & -1.67 & -2.13 & -0.65 \\
\hline Canada & -0.27 & -0.18 & -0.14 & 0.08 & 0.06 & 0.23 & -0.54 & -0.54 & -0.54 & -0.28 & -0.31 & -0.30 & -0.32 & 0.23 \\
\hline Germany $\backslash$ Euro Area & -0.55 & -0.50 & -0.57 & -0.73 & -0.72 & -0.71 & -1.96 & -1.96 & -1.96 & -1.78 & -1.59 & -1.71 & -1.53 & -0.50 \\
\hline Japan & -0.99 & -0.97 & -0.92 & -0.69 & -0.45 & -0.12 & -0.87 & -0.87 & -0.87 & -0.81 & -0.49 & -0.70 & -0.50 & -0.12 \\
\hline New Zealand & -1.22 & -1.27 & -1.23 & -1.32 & -1.63 & -1.35 & -1.47 & -1.47 & -1.47 & -1.55 & -1.74 & -1.54 & -1.72 & -1.22 \\
\hline Sweden & -0.63 & -0.66 & -0.63 & -1.17 & -0.89 & -1.17 & -1.43 & -1.43 & -1.43 & -1.64 & -1.11 & -1.64 & -1.17 & -0.63 \\
\hline Switzerland & -0.01 & 0.09 & -0.02 & -0.23 & -0.14 & -0.22 & -0.65 & -0.65 & -0.65 & -0.50 & -0.49 & -0.47 & -0.44 & 0.09 \\
\hline United Kingdom & -1.14 & -1.12 & -1.14 & -1.78 & -1.71 & -1.80 & -0.92 & -0.92 & -0.92 & -1.77 & -1.71 & -1.77 & -1.71 & -0.92 \\
\hline \multicolumn{15}{|c|}{ Panel B: Developing Countries } \\
\hline Czech Republic & -0.10 & -0.12 & -0.12 & -0.07 & -0.06 & -0.03 & -0.04 & -0.04 & -0.04 & -0.02 & -0.02 & -0.04 & -0.04 & -0.02 \\
\hline Hungary & -0.21 & 0.01 & -0.03 & -0.85 & -0.78 & -0.68 & -1.19 & -1.19 & -1.19 & -1.06 & -1.03 & -1.06 & -0.98 & 0.01 \\
\hline India & -0.97 & -0.98 & -0.98 & -0.97 & -0.97 & -1.04 & -1.36 & -1.36 & -1.36 & -1.16 & -1.30 & -1.23 & -1.35 & -0.97 \\
\hline Philip & 1.64 & $1.91^{b}$ & 1.63 & -0.89 & -2.90 & -1.01 & $0.94^{b}$ & $0.94^{b}$ & $0.94^{b}$ & $0.98^{b}$ & -0.39 & $1.01^{b}$ & -0.35 & 1.91 \\
\hline Singapore & -0.31 & -0.26 & -0.28 & 0.65 & -0.82 & 0.84 & -0.65 & -0.65 & -0.65 & -0.33 & -0.86 & -0.26 & -0.85 & 0.84 \\
\hline South Africa & $1.62^{a}$ & $1.51^{a}$ & $1.62^{a}$ & 0.44 & $1.49^{a}$ & 0.61 & -1.60 & -1.60 & -1.60 & $0.98^{a}$ & -1.88 & $0.82^{a}$ & -1.71 & $1.62^{a}$ \\
\hline Taiwan & -2.03 & -2.01 & -2.05 & -2.02 & -2.29 & -1.99 & $0.89^{b}$ & $0.89^{b}$ & $0.89^{b}$ & $0.72^{b}$ & 0.24 & $0.69^{b}$ & 0.15 & 0.89 \\
\hline Thailand & 0.30 & 0.26 & 0.27 & 0.97 & 0.98 & 0.88 & 0.12 & 0.12 & 0.12 & 0.89 & 0.93 & 0.84 & 1.02 & 1.02 \\
\hline
\end{tabular}




\section{Table 6}

\section{Portfolio-Level Forecasts Based on Unconditional Expectation of Factors: The Rolling Scheme}

The table presents statistical measures of out-of-sample forecast accuracy of linear factor models for exchange rate returns relative to a random walk with drift (RWD) benchmark (equation (2)). The one-month ahead forecasts of exchange rate returns for five forward discount-sorted portfolios are from rolling regressions with a eight-year window using unconditional expectations of risk factors. For each portfolio $j$ and competing model in equation $(i)(i=6,7, \ldots, 15)$, DMW denotes the Diebold and Mariano (1995) and West (1996) $\mathrm{MSFE}_{i}^{j}-t$ statistic based on the Newey and West (1987) estimator, which tests the null hypothesis of equal mean squared forecast error (MSFE) between the RWD and the competing model. RC denotes $\max _{i=6,7 \ldots, 15} \mathrm{MSFE}_{i}^{j}-t$ statistic for reality check (best model) following Clark and McCracken (2012), which tests the joint null hypothesis of no predictive ability across all competing models. One-sided (to the right) critical values are obtained using 10,000 fixed regressor bootstrap replications as in Clark and McCracken (2012). $a$ and $b$ denote statistical significance at the $5 \%$ and $10 \%$ levels, respectively. GW denotes the Giacomini and White (2006) $p_{i}^{j}$-value for pairwise test of equal conditional predictive ability. Numbers in parentheses show the proportion of times the competing model outperforms the RWD over the out-of-sample period. $*(\dagger)$ indicates that the GW test rejects the null hypothesis of equal conditional predictive ability at the $10 \%$ significance level and that the competing model outperforms (is outperformed by) the RWD more than $50 \%$ of the time. The out-of-sample forecasts are from November 1991 to November 2013.

\begin{tabular}{|c|c|c|c|c|c|c|c|c|c|c|c|}
\hline & \multicolumn{10}{|c|}{ Model } & \multirow[b]{2}{*}{$\mathrm{RC}$} \\
\hline & 6 & 7 & 8 & 9 & 10 & 11 & 12 & 13 & 14 & 15 & \\
\hline $\begin{array}{l}\text { DMW } \\
\text { GW }\end{array}$ & $\begin{array}{c}-1.84 \\
0.02^{\dagger} \\
(0.09)\end{array}$ & $\begin{array}{r}0.09 \\
0.74 \\
(0.69)\end{array}$ & $\begin{array}{c}-1.63 \\
0.03^{\dagger} \\
(0.10)\end{array}$ & $\begin{array}{r}-1.77 \\
0.01^{\dagger} \\
(0.12)\end{array}$ & $\begin{array}{c}\text { Port } \\
-1.93 \\
0.00^{\dagger} \\
(0.12)\end{array}$ & $\begin{array}{l}\text { lio } 1 \\
-1.74 \\
0.01^{\dagger} \\
(0.12)\end{array}$ & $\begin{array}{c}-2.25 \\
0.00^{\dagger} \\
(0.08)\end{array}$ & $\begin{array}{c}-2.03 \\
0.01^{\dagger} \\
(0.08)\end{array}$ & $\begin{array}{c}-2.13 \\
0.01^{\dagger} \\
(0.08)\end{array}$ & $\begin{array}{c}-2.08 \\
0.00^{\dagger} \\
(0.07)\end{array}$ & 0.09 \\
\hline $\begin{array}{l}\text { DMW } \\
\text { GW }\end{array}$ & $\begin{array}{r}1.37^{a} \\
0.31 \\
(0.99)\end{array}$ & $\begin{array}{r}0.67 \\
0.62 \\
(0.95)\end{array}$ & $\begin{array}{r}1.37^{b} \\
0.38 \\
(1.00)\end{array}$ & $\begin{array}{r}-0.30 \\
0.37 \\
(0.21)\end{array}$ & $\begin{array}{c}\text { Port } \\
-0.62 \\
0.03^{\dagger} \\
(0.24)\end{array}$ & $\begin{array}{l}\text { lio } 2 \\
-0.36 \\
0.34 \\
(0.21)\end{array}$ & $\begin{array}{r}-0.44 \\
0.28 \\
(0.21)\end{array}$ & $\begin{array}{c}-0.64 \\
0.03^{\dagger} \\
(0.23)\end{array}$ & $\begin{array}{r}-0.46 \\
0.29 \\
(0.20)\end{array}$ & $\begin{array}{c}-0.61 \\
0.04^{\dagger} \\
(0.23)\end{array}$ & $1.37^{b}$ \\
\hline $\begin{array}{l}\text { DMW } \\
\text { GW }\end{array}$ & $\begin{array}{r}-1.11 \\
0.56 \\
(0.01)\end{array}$ & $\begin{array}{c}-1.99 \\
0.07^{\dagger} \\
(0.03)\end{array}$ & $\begin{array}{r}-1.45 \\
0.43 \\
(0.00)\end{array}$ & $\begin{array}{r}-1.32 \\
0.53 \\
(0.01)\end{array}$ & $\begin{array}{r}\text { Port } \\
-1.46 \\
0.38 \\
(0.04)\end{array}$ & $\begin{array}{r}\text { lio } 3 \\
-1.33 \\
0.52 \\
(0.01)\end{array}$ & $\begin{array}{r}-1.37 \\
0.49 \\
(0.00)\end{array}$ & $\begin{array}{r}-1.77 \\
0.29 \\
(0.00)\end{array}$ & $\begin{array}{r}-1.42 \\
0.45 \\
(0.01)\end{array}$ & $\begin{array}{r}-1.78 \\
0.27 \\
(0.00)\end{array}$ & -1.11 \\
\hline $\begin{array}{l}\text { DMW } \\
\text { GW }\end{array}$ & $\begin{array}{r}0.78 \\
0.52 \\
(1.00)\end{array}$ & $\begin{array}{r}1.30^{b} \\
0.39 \\
(0.98)\end{array}$ & $\begin{array}{r}0.65 \\
0.67 \\
(1.00)\end{array}$ & $\begin{array}{r}-1.19 \\
0.36 \\
(0.06)\end{array}$ & $\begin{array}{r}\text { Port } \\
-1.28 \\
0.29 \\
(0.06)\end{array}$ & $\begin{array}{r}\text { lio } 4 \\
-1.15 \\
0.41 \\
(0.06)\end{array}$ & $\begin{array}{r}-0.88 \\
0.33 \\
(0.17)\end{array}$ & $\begin{array}{r}-0.47 \\
0.43 \\
(0.27)\end{array}$ & $\begin{array}{r}-0.93 \\
0.37 \\
(0.13)\end{array}$ & $\begin{array}{r}-0.48 \\
0.56 \\
(0.23)\end{array}$ & 1.30 \\
\hline $\begin{array}{l}\text { DMW } \\
\text { GW }\end{array}$ & $\begin{array}{c}-2.16 \\
0.00^{\dagger} \\
(0.07)\end{array}$ & $\begin{array}{r}-0.58 \\
0.30 \\
(0.16)\end{array}$ & $\begin{array}{c}-2.44 \\
0.00^{\dagger} \\
(0.05)\end{array}$ & $\begin{array}{c}-2.26 \\
0.00^{\dagger} \\
(0.08)\end{array}$ & $\begin{array}{r}\text { Port } \\
-2.28 \\
0.00^{\dagger} \\
(0.12)\end{array}$ & $\begin{array}{l}\text { lio } 5 \\
-2.21 \\
0.00^{\dagger} \\
(0.08)\end{array}$ & $\begin{array}{c}-2.11 \\
0.00^{\dagger} \\
(0.07)\end{array}$ & $\begin{array}{c}-2.29 \\
0.00^{\dagger} \\
(0.13)\end{array}$ & $\begin{array}{c}-2.11 \\
0.00^{\dagger} \\
(0.07)\end{array}$ & $\begin{array}{c}-2.29 \\
0.00^{\dagger} \\
(0.13)\end{array}$ & -0.58 \\
\hline
\end{tabular}


Table 7

Portfolio-Level Forecasts Based on Unconditional Expectations of Factors: The Recursive Scheme

The table presents the Diebold and Mariano (1995) and West (1996) $\mathrm{MSFE}_{i}^{j}$ - $t$ statistics for forward discountsorted currency portfolio $j$ based on the Newey and West (1987) estimator, which test the null hypothesis of equal mean squared forecast error (MSFE) between the random walk with drift benchmark (equation (2)) and the competing model in equation $(i)(i=6,7, \ldots, 15)$. The one-month ahead forecasts of exchange rate returns for five portfolios are from recursive regressions with a eight-year starting expanding window using unconditional expectations of risk factors. See also notes to Table 6 .

\begin{tabular}{|c|c|c|c|c|c|c|c|c|c|c|c|}
\hline \multirow[b]{2}{*}{ Portfolio } & \multicolumn{10}{|c|}{ Model } & \multirow[b]{2}{*}{$\mathrm{RC}$} \\
\hline & 6 & 7 & 8 & 9 & 10 & 11 & 12 & 13 & 14 & 15 & \\
\hline 1 & -1.57 & -1.50 & -1.56 & -1.85 & -2.01 & -1.65 & -2.22 & -2.15 & -2.08 & -2.13 & -1.50 \\
\hline 2 & 0.21 & -1.21 & -0.69 & 0.02 & -0.11 & 0.04 & -0.04 & -0.11 & -0.04 & -0.12 & 0.21 \\
\hline 3 & -1.14 & -0.92 & -1.02 & -0.46 & -0.56 & -0.46 & -0.51 & -0.62 & -0.49 & -0.60 & -0.46 \\
\hline 4 & -0.46 & -0.51 & -0.44 & -0.48 & -0.51 & -0.49 & -0.37 & -0.42 & -0.36 & -0.42 & -0.36 \\
\hline 5 & 0.51 & 0.40 & 0.37 & -1.82 & -1.99 & -1.81 & -2.32 & -2.00 & -2.32 & -2.02 & 0.51 \\
\hline
\end{tabular}




\section{Table 8}

\section{Economic Value of Exchange Rate Predictability}

The table summarizes the out-of-sample economic value of the linear factor models for exchange rate returns including a random walk with drift (RWD) benchmark (equation (2)). The one-month ahead forecasts of exchange rate returns are from rolling regressions with a eight-year window. The left panel contains results using forecasts based on unconditional expectations of risk factors, while the right panel contains results based on conditional expectations of risk factors. Using the forecasts of exchange rate returns from each model, a maximum expected return strategy subject to a target annualized portfolio volatility of $\sigma_{p}^{*}=10 \%$ is estimated for an investor who dynamically rebalances position on a monthly basis in one domestic (US) and 16 foreign bonds from developed and developing countries (Panel A) or eight foreign bonds from developed countries (Panel B). For each portfolio, the Sharpe ratio (SR) is the ratio of mean excess return to standard deviation of returns, while the Sortino ratio (SOR) is the ratio of mean excess return to standard deviation of negative returns only. $\Phi$ denotes the Fleming et al. (2001) measure of performance fee a risk averse investor with quadratic utility function is willing to pay for switching from the RWD strategy to a competing model strategy. $\Psi$ denotes the performance fee with mean-variance functional form for utility. $\Theta$ denotes the Goetzmann et al. (2007) manipulation-proof measure of performance after adjusting for risk. $\Phi, \Psi$, and $\Theta$ are computed with a relative risk aversion coefficient $\gamma=6$. The SR and SOR are annualized, while $\Phi, \Psi$, and $\Theta$ are reported in decimals per annum (i.e., $0.01=$ 1 annual percentage point). The out-of-sample economic value analysis is from November 1991 to November 2013.

\begin{tabular}{|c|c|c|c|c|c|c|c|c|c|c|}
\hline \multirow[b]{2}{*}{ Model } & \multicolumn{5}{|c|}{ Unconditional Expectations of Factors } & \multicolumn{5}{|c|}{ Conditional Expectations of Factors } \\
\hline & SR & SOR & $\Phi$ & $\Psi$ & $\Theta$ & SR & SOR & $\Phi$ & $\Psi$ & $\Theta$ \\
\hline \multicolumn{11}{|c|}{ Panel A: Developed and Developing Countries } \\
\hline 2 & 0.97 & 1.34 & & & & 0.97 & 1.34 & & & \\
\hline 3 & & & & & & 0.90 & 1.17 & -0.01 & -0.01 & -0.02 \\
\hline 4 & & & & & & 0.90 & 1.12 & -0.01 & -0.01 & -0.02 \\
\hline 5 & & & & & & 0.91 & 1.16 & -0.01 & -0.01 & -0.02 \\
\hline 6 & 0.93 & 1.33 & -0.01 & -0.01 & -0.01 & 0.85 & 1.10 & -0.02 & -0.02 & -0.03 \\
\hline 7 & 0.91 & 1.39 & -0.01 & -0.01 & -0.02 & 0.93 & 1.21 & -0.01 & -0.01 & -0.03 \\
\hline 8 & 0.91 & 1.28 & -0.01 & -0.01 & -0.01 & 0.88 & 1.10 & -0.02 & -0.02 & -0.03 \\
\hline 9 & 0.72 & 1.05 & -0.04 & -0.04 & -0.06 & 0.74 & 0.95 & -0.04 & -0.04 & -0.06 \\
\hline 10 & 0.70 & 0.97 & -0.05 & -0.05 & -0.07 & 0.74 & 0.95 & -0.04 & -0.04 & -0.06 \\
\hline 11 & 0.72 & 1.04 & -0.04 & -0.04 & -0.06 & 0.74 & 0.95 & -0.04 & -0.04 & -0.06 \\
\hline 12 & 0.70 & 1.08 & -0.05 & -0.05 & -0.07 & 0.73 & 0.96 & -0.04 & -0.04 & -0.07 \\
\hline 13 & 0.77 & 1.12 & -0.03 & -0.03 & -0.06 & 0.84 & 1.07 & -0.02 & -0.02 & -0.05 \\
\hline 14 & 0.79 & 1.18 & -0.03 & -0.03 & -0.05 & 0.81 & 1.09 & -0.03 & -0.03 & -0.05 \\
\hline 15 & 0.79 & 1.09 & -0.03 & -0.03 & -0.06 & 0.85 & 1.13 & -0.02 & -0.02 & -0.05 \\
\hline
\end{tabular}

Panel B: Developed Countries

\begin{tabular}{rrrrrrrrrrrr}
2 & 0.47 & 0.56 & & & & 0.47 & 0.56 & & & \\
3 & & & & & & 0.55 & 0.65 & -0.01 & 0.00 & -0.01 \\
4 & & & & & & 0.50 & 0.58 & 0.00 & 0.00 & -0.01 \\
5 & & & & & & 0.57 & 0.68 & -0.01 & -0.01 & -0.02 \\
6 & 0.38 & 0.46 & -0.01 & -0.01 & -0.02 & 0.52 & 0.63 & 0.00 & 0.00 & -0.01 \\
7 & 0.33 & 0.42 & -0.02 & -0.02 & -0.03 & 0.51 & 0.59 & 0.00 & 0.00 & -0.01 \\
8 & 0.31 & 0.37 & -0.02 & -0.02 & -0.03 & 0.57 & 0.69 & 0.01 & 0.01 & -0.01 \\
9 & 0.22 & 0.31 & -0.05 & -0.05 & -0.06 & 0.38 & 0.46 & -0.02 & -0.02 & -0.04 \\
10 & 0.24 & 0.30 & -0.04 & -0.04 & -0.06 & 0.38 & 0.46 & -0.02 & -0.02 & -0.04 \\
11 & 0.21 & 0.28 & -0.05 & -0.05 & -0.06 & 0.38 & 0.46 & -0.02 & -0.02 & -0.04 \\
12 & 0.21 & 0.28 & -0.05 & -0.05 & -0.07 & 0.43 & 0.54 & -0.02 & -0.01 & -0.03 \\
13 & 0.30 & 0.38 & -0.03 & -0.03 & -0.05 & 0.51 & 0.61 & 0.00 & 0.00 & -0.02 \\
14 & 0.26 & 0.36 & -0.04 & -0.04 & -0.05 & 0.49 & 0.61 & -0.01 & -0.01 & -0.02 \\
15 & 0.33 & 0.42 & -0.03 & -0.03 & -0.05 & 0.51 & 0.61 & 0.00 & 0.00 & -0.02 \\
& & & & & & & & & & \\
\hline \hline
\end{tabular}




\section{Appendix Tables}

Table A1

Combined Forecasts Based on Unconditional Expectations of Factors

The table presents the Theil (1996) U-statistics for currency $k$, which are the ratios of the root mean squared forecast error (RMSFE) of the competing linear factor model in equation $(i)(i=6,7, \ldots, 15)$ to the RMSFE of the random walk with drift (RWD) benchmark (equation (2)). Panels A and B report results for currencies from eight developed and eight developing countries, respectively. The one-month ahead combined forecasts of exchange rate returns for individual currencies are from recursive regressions with a eight-year starting expanding window and rolling regressions with a eight-year window using weights $\theta=0.92$ and $(1-\theta)=0.08$, respectively, and unconditional expectations of risk factors. The weights for combining the rolling and recursive scheme forecasts are computed as in Clark and McCracken (2009). The null hypothesis is that the competing model and the RWD provide equally accurate forecasts (i.e., $\mathrm{U}_{i}^{k}=1$ ), while the alternative hypothesis is that the competing model is more accurate than the RWD (i.e., $\mathrm{U}_{i}^{k}<1$ ). One-sided (to the left) critical values are obtained using 10,000 fixed regressor bootstrap replications as in Clark and McCracken (2012). $a$ and $b$ denote statistical significance at the $5 \%$ and $10 \%$ levels, respectively. The out-of-sample forecasts are from November 1991 to November 2013.

\begin{tabular}{|c|c|c|c|c|c|c|c|c|c|c|}
\hline \multirow[b]{2}{*}{ Country } & \multicolumn{10}{|c|}{ Model } \\
\hline & 6 & 7 & 8 & 9 & 10 & 11 & 12 & 13 & 14 & 15 \\
\hline \multicolumn{11}{|c|}{ Panel A: Developed Countries } \\
\hline Australia & 1.000 & 1.001 & 1.000 & 1.003 & 1.002 & 1.003 & 1.003 & 1.002 & 1.003 & 1.002 \\
\hline Canada & 0.999 & 1.000 & 1.000 & 1.001 & 1.001 & 1.001 & 1.000 & 1.000 & 1.000 & 1.000 \\
\hline Germany $\backslash$ Euro Area & 1.000 & 1.001 & 1.000 & 1.004 & 1.004 & 1.004 & 1.004 & 1.005 & 1.004 & 1.005 \\
\hline Japan & 1.002 & 1.002 & 1.002 & 1.001 & $0.999^{b}$ & 1.003 & 1.003 & 1.000 & 1.005 & 1.002 \\
\hline New Zealand & 1.000 & 1.001 & 1.000 & 1.001 & 1.000 & 1.001 & 1.001 & 1.000 & 0.999 & 0.999 \\
\hline Sweden & 1.001 & 1.001 & 1.001 & 1.013 & 1.013 & 1.013 & 1.010 & 1.010 & 1.010 & 1.011 \\
\hline Switzerland & 1.000 & 1.000 & 1.000 & 1.006 & 1.007 & 1.005 & 1.005 & 1.006 & 1.005 & 1.006 \\
\hline United Kingdom & 1.001 & 1.000 & 1.001 & 1.005 & 1.005 & 1.005 & 1.003 & 1.003 & 1.003 & 1.003 \\
\hline \multicolumn{11}{|c|}{ Panel B: Developing Countries } \\
\hline Czech Republic & 1.000 & 1.000 & 1.000 & 1.000 & 1.000 & 1.000 & 1.000 & 1.000 & 0.999 & 0.999 \\
\hline Hungary & 1.000 & 1.001 & 1.000 & 1.002 & 1.002 & 1.002 & 1.002 & 1.002 & 1.002 & 1.002 \\
\hline India & 1.000 & 1.001 & 1.000 & 1.004 & 1.004 & 1.003 & 1.003 & 1.002 & 1.002 & 1.001 \\
\hline Philippines & 1.002 & 1.047 & 1.002 & $0.969^{a}$ & $0.974^{a}$ & $0.970^{a}$ & $0.980^{a}$ & 1.008 & $0.981^{a}$ & 1.008 \\
\hline Singapore & 0.998 & 0.997 & 0.999 & 1.002 & 1.002 & 1.002 & $0.998^{b}$ & $0.998^{b}$ & $0.999^{b}$ & $0.999^{b}$ \\
\hline South Africa & 1.000 & $0.994^{a}$ & 1.000 & 1.050 & 1.064 & 1.050 & $0.993^{a}$ & 1.127 & $0.991^{a}$ & 1.116 \\
\hline Taiwan & 1.000 & 1.007 & 1.000 & $0.991^{b}$ & $0.991^{b}$ & $0.991^{b}$ & $0.992^{b}$ & $0.993^{b}$ & $0.993^{b}$ & $0.994^{b}$ \\
\hline Thailand & $0.993^{a}$ & 0.994 & $0.993^{a}$ & 0.998 & 0.998 & 0.998 & 0.992 & 0.989 & 0.992 & 0.988 \\
\hline
\end{tabular}


Table A2

\section{Combined Forecasts Based on Conditional Expectations of Factors}

The table presents the Theil (1996) U-statistics for currency $k$, which are the ratios of the root mean squared forecast error (RMSFE) of the competing linear factor model in equation $(i)(i=3,4, \ldots, 15)$ to the RMSFE of the random walk with drift benchmark (equation (2)). The one-month ahead combined forecasts of exchange rate returns for individual currencies are from recursive regressions with a eight-year starting expanding window and rolling regressions with a eight-year window using weights $\theta=0.92$ and $(1-\theta)=0.08$, respectively, and conditional expectations of risk factors. See also notes to Table A1.

\begin{tabular}{|c|c|c|c|c|c|c|c|c|c|c|c|c|c|}
\hline \multirow[b]{2}{*}{ Country } & \multicolumn{13}{|c|}{ Model } \\
\hline & 3 & 4 & 5 & 6 & 7 & 8 & 9 & 10 & 11 & 12 & 13 & 14 & 15 \\
\hline \multicolumn{14}{|c|}{ Panel A: Developed Countries } \\
\hline Australia & 1.001 & 1.002 & 1.001 & 1.001 & 1.003 & 1.002 & 1.006 & 1.006 & 1.006 & 1.005 & 1.004 & 1.005 & 1.005 \\
\hline Canada & 1.000 & 1.000 & 1.000 & 1.000 & 1.000 & 1.000 & 1.002 & 1.002 & 1.002 & 1.001 & 1.001 & 1.001 & 1.001 \\
\hline Germany $\backslash$ Euro Area & 1.002 & 1.001 & 1.002 & 1.004 & 1.004 & 1.004 & 1.003 & 1.003 & 1.003 & 1.004 & 1.004 & 1.004 & 1.004 \\
\hline Japan & 1.022 & 1.027 & 1.018 & 1.008 & 1.008 & 1.001 & 1.031 & 1.031 & 1.031 & 1.021 & 1.012 & 1.014 & 1.011 \\
\hline New Zealand & 1.005 & 1.006 & 1.005 & 1.005 & 1.009 & 1.006 & 1.008 & 1.008 & 1.008 & 1.007 & 1.005 & 1.006 & 1.004 \\
\hline Sweden & 1.005 & 1.005 & 1.005 & 1.012 & 1.011 & 1.012 & 1.007 & 1.007 & 1.007 & 1.012 & 1.009 & 1.012 & 1.009 \\
\hline Switzerland & 1.000 & $0.999^{a}$ & 1.000 & 1.002 & 1.001 & 1.001 & 1.001 & 1.001 & 1.001 & 1.002 & 1.001 & 1.001 & 1.001 \\
\hline United Kingdom & 1.016 & 1.016 & 1.016 & 1.026 & 1.026 & 1.026 & 1.010 & 1.010 & 1.010 & 1.023 & 1.023 & 1.023 & 1.022 \\
\hline
\end{tabular}

Panel B: Developing Countries

\begin{tabular}{|c|c|c|c|c|c|c|c|c|c|c|c|c|c|}
\hline zech Rep & 1.001 & 1.001 & 1.001 & 1.001 & 1.001 & 1.001 & 1.001 & 1.001 & 1.001 & 1.001 & 1.001 & 1.001 & 1.001 \\
\hline Hungary & 1.000 & 1.000 & 1.000 & 1.001 & 1.001 & 1.000 & 1.002 & 1.002 & 1.002 & 1.002 & 1.002 & 1.002 & 1.002 \\
\hline India & 1004 & 1.004 & 1004 & 1005 & 8 & 007 & 1.008 & 1.008 & 008 & 8 & 9 & 1.009 & 1.010 \\
\hline Philippines & $0.993^{a}$ & $0.989^{a}$ & $0.993^{a}$ & 1.003 & 1.047 & 1.003 & $0.968^{a}$ & $0.968^{a}$ & $0.968^{a}$ & $0.980^{b}$ & 1.009 & $0.980^{a}$ & .009 \\
\hline & & & & 0.8 & & $0.998^{b}$ & 1.007 & & & & & 1.001 & 020 \\
\hline South Africa & $985^{a}$ & $0.984^{a}$ & $0.985^{a}$ & 0.997 & $0.984^{a}$ & 0.997 & 1.017 & 1.017 & 1.017 & $0.994^{a}$ & 1.009 & $0.995^{a}$ & .006 \\
\hline Taiwan & 1.011 & 1.010 & 1.011 & 1.010 & 1.021 & 1.010 & 0.995 & 0.995 & $0.995^{b}$ & $0.995^{b}$ & 0.999 & 0.996 & 0.999 \\
\hline Thailand & 0.999 & 0.999 & 0.999 & $0.996^{b}$ & 0.997 & 0.996 & 0.998 & 0.998 & 0.998 & 0.996 & 0.994 & 0.996 & 0.99 \\
\hline
\end{tabular}


Table A3

\section{Rolling Scheme Forecasts Based on Unconditional Expectations of Factors: Purchasing Power Parity Benchmark}

The table presents statistical measures of out-of-sample forecast accuracy of linear factor models for exchange rate returns relative to a purchasing power parity (PPP) benchmark (equation (33)). The one-month ahead forecasts of exchange rate returns for individual currencies are from rolling regressions with a eight-year window using unconditional expectations of risk factors. Panels A and B report results for currencies from eight developed and seven developing countries, respectively. For each currency $k$ and competing model in equation $(i)$ $(i=6,7, \ldots, 15)$, DMW denotes the Diebold and Mariano (1995) and West (1996) $\mathrm{MSFE}_{i}^{k}-t$ statistic based on the Andrews and Monahan (1992) estimator, which tests the null hypothesis of equal mean squared forecast error (MSFE) between the PPP and the competing model. $a$ and $b$ denote statistical significance at the $5 \%$ and $10 \%$ levels, respectively. GW denotes the Giacomini and White (2006) $p_{i}^{k}$-value for pairwise test of equal conditional predictive ability. Numbers in parentheses show the proportion of times the competing model outperforms the PPP over the out-of-sample period. $*(\dagger)$ indicates that the GW test rejects the null hypothesis of equal conditional predictive ability at the $10 \%$ significance level and that the competing model outperforms (is outperformed by) the PPP more than $50 \%$ of the time. The out-of-sample forecasts are from November 1991 to November 2013.

\begin{tabular}{|c|c|c|c|c|c|c|c|c|c|c|}
\hline & \multicolumn{10}{|c|}{ Model } \\
\hline & 6 & 7 & 8 & 9 & 10 & 11 & 12 & 13 & 14 & 15 \\
\hline \multicolumn{11}{|c|}{ Panel A: Developed Countries } \\
\hline \multicolumn{11}{|c|}{ Australia } \\
\hline DMW & 1.45 & 1.37 & 1.32 & 0.48 & 0.58 & 0.52 & 0.47 & 0.63 & 0.35 & 0.43 \\
\hline GW & $\begin{array}{c}0.02^{*} \\
(0.83)\end{array}$ & $\begin{array}{c}0.02^{*} \\
(0.81)\end{array}$ & $\begin{array}{c}0.02 * \\
(0.82)\end{array}$ & $\begin{array}{r}0.16 \\
(0.69)\end{array}$ & $\begin{array}{r}0.15 \\
(0.72)\end{array}$ & $\begin{array}{r}0.20 \\
(0.72)\end{array}$ & $\begin{array}{r}0.24 \\
(0.72)\end{array}$ & $\begin{array}{r}0.16 \\
(0.74)\end{array}$ & $\begin{array}{r}0.32 \\
(0.68)\end{array}$ & $\begin{array}{r}0.23 \\
(0.70)\end{array}$ \\
\hline \multicolumn{11}{|c|}{ Canada } \\
\hline DMW & 0.85 & 0.60 & 0.64 & 0.31 & 0.20 & 0.44 & 0.29 & 0.17 & 0.21 & 0.13 \\
\hline GW & $\begin{array}{c}0.00^{*} \\
(0.70)\end{array}$ & $\begin{array}{c}0.00^{*} \\
(0.65)\end{array}$ & $\begin{array}{c}0.00^{*} \\
(0.66)\end{array}$ & $\begin{array}{r}0.25 \\
(0.66)\end{array}$ & $\begin{array}{r}0.32 \\
(0.62)\end{array}$ & $\begin{array}{r}0.26 \\
(0.72)\end{array}$ & $\begin{array}{r}0.18 \\
(0.64)\end{array}$ & $\begin{array}{r}0.14 \\
(0.55)\end{array}$ & $\begin{array}{r}0.23 \\
(0.61)\end{array}$ & $\begin{array}{r}0.24 \\
(0.56)\end{array}$ \\
\hline $\begin{array}{l}\text { DMW } \\
\text { GW }\end{array}$ & $\begin{array}{r}-0.21 \\
0.32 \\
(0.32)\end{array}$ & $\begin{array}{r}-0.35 \\
0.22 \\
(0.28)\end{array}$ & $\begin{array}{r}-0.19 \\
0.32 \\
(0.32)\end{array}$ & $\begin{array}{r}\text { Germ } \\
-0.85 \\
0.50 \\
(0.11)\end{array}$ & $\begin{array}{c}\text { any } \backslash \text { Euro } \\
-0.60 \\
0.60 \\
(0.15)\end{array}$ & $\begin{array}{r}\text { Area } \\
-0.89 \\
0.48 \\
(0.10)\end{array}$ & $\begin{array}{r}-1.15 \\
0.29 \\
(0.08)\end{array}$ & $\begin{array}{r}-1.01 \\
0.40 \\
(0.07)\end{array}$ & $\begin{array}{r}-1.18 \\
0.29 \\
(0.07)\end{array}$ & $\begin{array}{r}-1.09 \\
0.37 \\
(0.06)\end{array}$ \\
\hline \multicolumn{11}{|c|}{ Japan } \\
\hline $\begin{array}{l}\text { DMW } \\
\text { GW }\end{array}$ & $\begin{array}{r}0.69 \\
0.10^{*} \\
(0.73)\end{array}$ & $\begin{array}{r}0.74 \\
0.21 \\
(0.80)\end{array}$ & $\begin{array}{c}0.81 \\
0.01^{*} \\
(0.75)\end{array}$ & $\begin{array}{r}-0.04 \\
0.41 \\
(0.47)\end{array}$ & $\begin{array}{r}0.78 \\
0.18 \\
(0.84)\end{array}$ & $\begin{array}{r}-0.14 \\
0.35 \\
(0.40)\end{array}$ & $\begin{array}{r}-0.07 \\
0.27 \\
(0.43)\end{array}$ & $\begin{array}{r}0.60 \\
0.16 \\
(0.74)\end{array}$ & $\begin{array}{r}-0.40 \\
0.06^{\dagger} \\
(0.33)\end{array}$ & $\begin{array}{r}0.42 \\
0.13 \\
(0.65)\end{array}$ \\
\hline \multicolumn{11}{|c|}{ New Zealand } \\
\hline $\begin{array}{l}\text { DMW } \\
\text { GW }\end{array}$ & $\begin{array}{r}0.70 \\
0.23 \\
(0.84)\end{array}$ & $\begin{array}{r}0.71 \\
0.19 \\
(0.85)\end{array}$ & $\begin{array}{r}0.60 \\
0.29 \\
(0.84)\end{array}$ & $\begin{array}{r}0.23 \\
0.10 \\
(0.68)\end{array}$ & $\begin{array}{r}0.29 \\
0.13 \\
(0.73)\end{array}$ & $\begin{array}{r}0.14 \\
0.10 \\
(0.62)\end{array}$ & $\begin{array}{r}0.27 \\
0.11 \\
(0.71)\end{array}$ & $\begin{array}{r}0.95 \\
0.19 \\
(0.88)\end{array}$ & $\begin{array}{r}1.07 \\
0.22 \\
(0.90)\end{array}$ & $\begin{array}{r}1.15 \\
0.23 \\
(0.91)\end{array}$ \\
\hline $\begin{array}{l}\text { DMW } \\
\text { GW }\end{array}$ & $\begin{array}{c}-0.10 \\
0.01^{\dagger} \\
(0.42)\end{array}$ & $\begin{array}{c}-0.19 \\
0.00^{\dagger} \\
(0.40)\end{array}$ & $\begin{array}{c}-0.09 \\
0.01^{\dagger} \\
(0.42)\end{array}$ & $\begin{array}{r}-1.23 \\
0.19 \\
(0.05)\end{array}$ & $\begin{array}{r}\text { Sweden } \\
-0.83 \\
0.26 \\
(0.11)\end{array}$ & $\begin{array}{r}-1.24 \\
0.18 \\
(0.05)\end{array}$ & $\begin{array}{r}-0.88 \\
0.17 \\
(0.16)\end{array}$ & $\begin{array}{c}-1.07 \\
0.01^{\dagger} \\
(0.17)\end{array}$ & $\begin{array}{r}-0.81 \\
0.16 \\
(0.18)\end{array}$ & $\begin{array}{r}-1.10 \\
0.01^{\dagger} \\
(0.17)\end{array}$ \\
\hline \multicolumn{11}{|c|}{ Switzerland } \\
\hline $\begin{array}{l}\text { DMW } \\
\text { GW }\end{array}$ & $\begin{array}{r}0.79 \\
0.37 \\
(0.85)\end{array}$ & $\begin{array}{r}0.79 \\
0.42 \\
(0.87)\end{array}$ & $\begin{array}{r}0.82 \\
0.42 \\
(0.86)\end{array}$ & $\begin{array}{r}0.55 \\
0.84 \\
(1.00)\end{array}$ & $\begin{array}{r}0.43 \\
0.84 \\
(0.93)\end{array}$ & $\begin{array}{r}0.54 \\
0.82 \\
(0.98)\end{array}$ & $\begin{array}{r}0.46 \\
0.85 \\
(0.97)\end{array}$ & $\begin{array}{r}0.31 \\
0.84 \\
(0.88)\end{array}$ & $\begin{array}{r}0.51 \\
0.83 \\
(0.98)\end{array}$ & $\begin{array}{r}0.35 \\
0.85 \\
(0.91)\end{array}$ \\
\hline \multicolumn{11}{|c|}{ United Kingdom } \\
\hline DMW & -0.13 & -0.20 & -0.21 & -0.83 & -0.79 & -0.86 & -0.83 & -0.85 & -0.77 & -0.79 \\
\hline GW & $\begin{array}{r}0.34 \\
(0.34)\end{array}$ & $\begin{array}{r}0.23 \\
(0.32)\end{array}$ & $\begin{array}{r}0.32 \\
(0.32)\end{array}$ & $\begin{array}{r}0.26 \\
(0.10)\end{array}$ & $\begin{array}{r}0.20 \\
(0.12)\end{array}$ & $\begin{array}{r}0.25 \\
(0.10)\end{array}$ & $\begin{array}{r}0.28 \\
(0.09)\end{array}$ & $\begin{array}{r}0.18 \\
(0.11)\end{array}$ & $\begin{array}{r}0.54 \\
(0.05)\end{array}$ & $\begin{array}{r}0.36 \\
(0.08)\end{array}$ \\
\hline
\end{tabular}


Table A3 - Continued

\begin{tabular}{|c|c|c|c|c|c|c|c|c|c|c|}
\hline & \multicolumn{10}{|c|}{ Model } \\
\hline & 6 & 7 & 8 & 9 & 10 & 11 & 12 & 13 & 14 & 15 \\
\hline \multicolumn{11}{|c|}{ Panel B: Developing Countries } \\
\hline \multicolumn{11}{|c|}{ Czech Republic } \\
\hline DMW & -1.03 & -0.96 & -1.01 & -0.87 & -1.01 & -0.88 & -0.88 & -1.09 & -0.93 & -1.14 \\
\hline GW & 0.44 & 0.48 & 0.46 & 0.60 & 0.51 & 0.59 & 0.58 & 0.46 & 0.56 & 0.44 \\
\hline & $(0.10)$ & $(0.10)$ & $(0.10)$ & $(0.01)$ & $(0.01)$ & $(0.01)$ & $(0.01)$ & $(0.01)$ & $(0.01)$ & $(0.01)$ \\
\hline \multicolumn{11}{|c|}{ Hungary } \\
\hline DMW & $-1.96^{a}$ & $-2.00^{a}$ & $-1.99^{a}$ & $-2.04^{a}$ & $-2.10^{a}$ & $-2.06^{a}$ & $-1.94^{a}$ & $-2.07^{a}$ & $-2.00^{a}$ & $-2.06^{a}$ \\
\hline GW & 0.17 & 0.15 & 0.16 & 0.14 & 0.13 & 0.14 & 0.18 & 0.14 & 0.16 & 0.14 \\
\hline & $(0.01)$ & $(0.01)$ & $(0.01)$ & $(0.01)$ & $(0.01)$ & $(0.01)$ & $(0.01)$ & $(0.03)$ & $(0.01)$ & $(0.03)$ \\
\hline \multirow{2}{*}{\multicolumn{11}{|c|}{$\begin{array}{l}\text { India } \\
-1.18\end{array}$}} \\
\hline & & & & & & & & & & \\
\hline GW & 0.82 & 0.88 & 0.81 & 0.46 & 0.46 & 0.49 & 0.49 & 0.43 & 0.53 & 0.51 \\
\hline & $(0.04)$ & $(0.02)$ & $(0.04)$ & $(0.04)$ & $(0.04)$ & $(0.01)$ & $(0.02)$ & $(0.13)$ & $(0.00)$ & $(0.11)$ \\
\hline \multicolumn{11}{|c|}{ Philippines } \\
\hline DMW & 0.12 & -0.77 & 0.14 & $-1.68^{b}$ & -1.58 & $-1.68^{b}$ & $-1.70^{b}$ & $-1.74^{b}$ & $-1.84^{b}$ & $-1.83^{b}$ \\
\hline GW & 0.76 & $0.06^{\dagger}$ & 0.74 & $0.06^{\dagger}$ & 0.10 & $0.07^{\dagger}$ & $0.01^{\dagger}$ & $0.01^{\dagger}$ & $0.00^{\dagger}$ & $0.01^{\dagger}$ \\
\hline & $(0.78)$ & $(0.36)$ & $(0.79)$ & $(0.11)$ & $(0.10)$ & $(0.10)$ & $(0.14)$ & $(0.13)$ & $(0.12)$ & $(0.13)$ \\
\hline \multicolumn{11}{|c|}{ Singapore } \\
\hline DMW & 1.41 & 1.57 & 1.47 & 0.91 & 0.91 & 0.95 & 1.51 & 1.32 & 1.42 & 1.36 \\
\hline GW & 0.28 & 0.13 & 0.25 & 0.65 & 0.63 & 0.61 & 0.32 & 0.41 & 0.36 & 0.39 \\
\hline & $(0.98)$ & $(0.94)$ & $(0.98)$ & $(1.00)$ & $(1.00)$ & $(0.99)$ & $(1.00)$ & $(1.00)$ & $(1.00)$ & $(1.00)$ \\
\hline \multicolumn{11}{|c|}{ South Africa } \\
\hline DMW & 0.49 & 1.40 & 0.43 & 0.82 & -0.59 & 0.70 & -0.58 & $-2.28^{a}$ & 0.72 & $-2.33^{a}$ \\
\hline GW & $0.00^{*}$ & $0.01^{*}$ & $0.00^{*}$ & $0.00^{*}$ & 0.14 & $0.00^{*}$ & 0.13 & $0.00^{\dagger}$ & $0.00^{*}$ & $0.00^{\dagger}$ \\
\hline & $(0.70)$ & $(0.85)$ & $(0.70)$ & $(0.78)$ & $(0.20)$ & $(0.77)$ & $(0.14)$ & $(0.05)$ & $(0.80)$ & $(0.05)$ \\
\hline \multicolumn{11}{|c|}{ Thailand } \\
\hline DMW & 1.18 & 1.12 & 1.21 & 0.20 & 0.22 & 0.21 & 0.40 & 0.46 & 0.37 & 0.43 \\
\hline GW & 0.46 & 0.51 & 0.44 & 0.93 & 0.93 & 0.93 & 0.85 & 0.85 & 0.87 & 0.86 \\
\hline & $(1.00)$ & (1.00) & $(1.00)$ & $(0.81)$ & $(0.84)$ & $(0.83)$ & $(0.92)$ & $(0.93)$ & $(0.92)$ & $(0.92)$ \\
\hline
\end{tabular}


Table A4

\section{Recursive Scheme Forecasts Based on Unconditional Expectations of Factors: Purchasing Power Parity Benchmark}

The table presents the Diebold and Mariano (1995) and West (1996) $\mathrm{MSFE}_{i}^{k}-t$ statistics for currency $k$ based on the Andrews and Monahan (1992) estimator, which test the null hypothesis of equal mean squared forecast error (MSFE) between the purchasing power parity benchmark (equation (33)) and the competing model in equation $(i)(i=6,7, \ldots, 15)$. The one-month ahead forecasts of exchange rate returns for individual currencies are from recursive regressions with a eight-year starting expanding window using unconditional expectations of risk factors. See also notes to Table A3.

\begin{tabular}{|c|c|c|c|c|c|c|c|c|c|c|}
\hline \multirow[b]{2}{*}{ Country } & \multicolumn{10}{|c|}{ Model } \\
\hline & 6 & 7 & 8 & 9 & 10 & 11 & 12 & 13 & 14 & 15 \\
\hline \multicolumn{11}{|c|}{ Panel A: Developed Countries } \\
\hline Australia & 0.79 & 0.54 & 0.77 & 0.08 & 0.30 & 0.14 & 0.15 & 0.32 & 0.20 & 0.30 \\
\hline Canada & 0.49 & 0.56 & 0.52 & 0.00 & 0.03 & 0.03 & 0.28 & 0.33 & 0.23 & 0.27 \\
\hline Germany $\backslash$ Euro Area & -0.87 & -0.91 & -0.88 & -1.55 & -1.54 & -1.54 & -1.50 & -1.58 & -1.51 & -1.59 \\
\hline Japan & -0.87 & -0.94 & -0.92 & -0.49 & -0.39 & -0.58 & -0.64 & -0.55 & -0.80 & -0.81 \\
\hline New Zealand & 0.40 & 0.18 & 0.39 & 0.23 & 0.28 & 0.24 & 0.21 & 0.21 & 0.24 & 0.21 \\
\hline Sweden & -0.95 & -0.90 & -0.94 & $-2.14^{a}$ & $-2.11^{a}$ & $-2.14^{a}$ & $-2.72^{a}$ & $-3.36^{a}$ & $-2.80^{a}$ & $-3.40^{a}$ \\
\hline Switzerland & -0.42 & -0.40 & -0.43 & -1.33 & -1.49 & -1.27 & -1.30 & -1.38 & -1.23 & -1.37 \\
\hline United Kingdom & -1.35 & -1.27 & -1.36 & $-2.10^{a}$ & $-2.08^{a}$ & $-2.09^{a}$ & $-1.80^{b}$ & $-1.75^{b}$ & $-1.83^{b}$ & $-1.79^{b}$ \\
\hline \multicolumn{11}{|c|}{ Panel B: Developing Countries } \\
\hline Czech Republic & 0.80 & 0.79 & 0.80 & 0.78 & 0.79 & 0.79 & 0.80 & 0.81 & 0.83 & 0.84 \\
\hline Hungary & 0.52 & 0.45 & 0.51 & 0.34 & 0.28 & 0.30 & 0.37 & 0.31 & 0.35 & 0.32 \\
\hline India & 0.25 & 0.12 & 0.31 & -0.11 & -0.10 & -0.07 & 0.00 & 0.08 & 0.16 & 0.25 \\
\hline Philippines & 1.45 & -0.27 & 1.44 & 1.51 & 1.41 & 1.48 & 1.48 & 0.98 & 1.48 & 1.00 \\
\hline Singapore & 0.29 & 0.49 & 0.27 & -0.26 & -0.28 & -0.27 & 0.12 & 0.11 & 0.05 & 0.08 \\
\hline South Africa & -0.19 & 0.78 & -0.21 & $-2.12^{a}$ & $-2.30^{a}$ & $-2.11^{a}$ & 0.78 & $-2.35^{a}$ & 0.83 & $-2.35^{a}$ \\
\hline Thailand & $3.14^{a}$ & $3.17^{a}$ & $3.14^{a}$ & $3.09^{a}$ & $3.10^{a}$ & $3.10^{a}$ & $3.13^{a}$ & $3.13^{a}$ & $3.13^{a}$ & $3.14^{a}$ \\
\hline
\end{tabular}




\section{Table A5}

\section{Long-Horizon Forecasts Based on Unconditional Expectations of Factors}

The table presents the Diebold and Mariano (1995) and West (1996) $\mathrm{MSFE}_{i}^{k}-t$ statistics for currency $k$ based on the Newey and West (1987) estimator, which test the null hypothesis of equal mean squared forecast error (MSFE) between the random walk with drift benchmark (equation (2)) and the competing model in equation (i) $(i=6,7, \ldots, 15)$. The $l$-month ahead forecasts of exchange rate returns are from rolling regressions with a eight-year window using unconditional expectations of risk factors. Panels A and B report results for currencies from eight developed and eight developing countries, respectively. RC denotes $\max _{i=6,7 \ldots, 15} \mathrm{MSFE}_{i}^{k}-t$ statistic for reality check (best model) following Clark and McCracken (2012), which tests the joint null hypothesis of no predictive ability across all competing models. One-sided (to the right) critical values are obtained using 10,000 fixed regressor bootstrap replications as in Clark and McCracken (2012). $a$ and $b$ denote statistical significance at the $5 \%$ and $10 \%$ levels, respectively. The out-of-sample forecasts are from November 1992 to November 2013.

\begin{tabular}{|c|c|c|c|c|c|c|c|c|c|c|c|}
\hline \multirow[b]{2}{*}{$l$} & \multicolumn{10}{|c|}{ Model } & \multirow[b]{2}{*}{$\mathrm{RC}$} \\
\hline & 6 & 7 & 8 & 9 & 10 & 11 & 12 & 13 & 14 & 15 & \\
\hline \multicolumn{12}{|c|}{ Panel A: Developed Countries } \\
\hline \multicolumn{12}{|c|}{ Australia } \\
\hline 12 & -2.10 & 0.94 & -1.74 & 0.59 & 0.61 & 0.57 & 0.35 & 0.22 & 0.36 & 0.20 & 0.94 \\
\hline 24 & -0.87 & 2.45 & -1.36 & 0.83 & 0.91 & 0.81 & 1.00 & 1.00 & 0.88 & 0.88 & 2.45 \\
\hline \multicolumn{12}{|c|}{ Canada } \\
\hline 12 & -2.98 & -0.57 & -2.69 & $2.05^{b}$ & $2.17^{b}$ & 2.00 & 1.87 & 2.03 & 1.73 & 1.80 & 2.17 \\
\hline 24 & -1.95 & -0.90 & 0.69 & 1.57 & 1.66 & 1.55 & 1.52 & 1.65 & 1.50 & 1.63 & 1.66 \\
\hline \multicolumn{12}{|c|}{ Germany $\backslash$ Euro Area } \\
\hline 12 & -1.90 & -0.64 & -2.05 & 1.81 & 1.94 & 1.80 & 1.78 & 1.44 & 1.71 & 1.49 & 1.94 \\
\hline 24 & 1.01 & 2.10 & 1.17 & 2.01 & 2.04 & 2.01 & 2.02 & 2.05 & 2.02 & 2.07 & 2.10 \\
\hline \multicolumn{12}{|c|}{ Japan } \\
\hline 12 & -0.96 & -0.34 & -1.06 & -0.12 & -0.08 & -0.15 & -0.12 & -0.28 & -0.25 & -0.35 & -0.08 \\
\hline 24 & 0.26 & -1.36 & 0.52 & -0.28 & -0.26 & -0.28 & -0.41 & -0.42 & -0.45 & -0.45 & 0.52 \\
\hline \multicolumn{12}{|c|}{ New Zealand } \\
\hline 12 & -0.42 & 0.74 & -0.42 & -0.63 & -0.67 & -0.67 & -0.27 & -0.29 & -0.12 & -0.06 & 0.74 \\
\hline 24 & -0.36 & 2.34 & -1.35 & -0.76 & -0.70 & -0.78 & -0.98 & -0.79 & -1.01 & -0.85 & 2.34 \\
\hline \multicolumn{12}{|c|}{ Sweden } \\
\hline 12 & 0.52 & -0.05 & 0.61 & -1.40 & -1.30 & -1.41 & -1.38 & -1.42 & -1.35 & -1.42 & 0.61 \\
\hline 24 & -0.13 & -0.88 & 0.33 & -0.49 & -0.42 & -0.49 & -0.34 & -0.49 & -0.25 & -0.36 & 0.33 \\
\hline \multicolumn{12}{|c|}{ Switzerland } \\
\hline 12 & -1.65 & -1.39 & -1.76 & 1.80 & 1.88 & 1.78 & 1.67 & 1.40 & 1.63 & 1.39 & 1.88 \\
\hline 24 & -1.66 & 0.83 & -1.46 & 2.01 & 2.07 & 2.03 & 2.04 & 2.02 & 2.08 & 2.12 & 2.12 \\
\hline \multicolumn{12}{|c|}{ United Kingdom } \\
\hline 12 & -2.84 & -0.46 & -2.79 & -1.90 & -1.89 & -1.91 & -1.99 & -1.67 & -2.00 & -1.67 & -0.46 \\
\hline 24 & -3.42 & 0.45 & -3.67 & -0.66 & -0.68 & -0.69 & -0.53 & -0.59 & -0.48 & -0.60 & 0.45 \\
\hline
\end{tabular}


Table A5 - Continued

\begin{tabular}{|c|c|c|c|c|c|c|c|c|c|c|c|}
\hline \multirow[b]{2}{*}{$l$} & \multicolumn{10}{|c|}{ Model } & \multirow[b]{2}{*}{$\mathrm{RC}$} \\
\hline & 6 & 7 & 8 & 9 & 10 & 11 & 12 & 13 & 14 & 15 & \\
\hline \multicolumn{12}{|c|}{ Panel B: Developing Countries } \\
\hline \multicolumn{12}{|c|}{ Czech Republic } \\
\hline 12 & -1.51 & -1.81 & -1.71 & 2.45 & $2.64^{b}$ & $2.45^{b}$ & $2.86^{a}$ & $2.73^{b}$ & $2.85^{b}$ & $2.77^{b}$ & $2.86^{b}$ \\
\hline 24 & -0.30 & 0.15 & -0.33 & 1.71 & 1.66 & 1.75 & 1.92 & 2.02 & 1.91 & 1.99 & 2.02 \\
\hline \multicolumn{12}{|c|}{ Hungary } \\
\hline 12 & -0.03 & 0.60 & 0.03 & 1.78 & 1.73 & 1.82 & 1.94 & 1.93 & 1.95 & 1.65 & 1.95 \\
\hline 24 & 2.45 & $3.79^{b}$ & 2.58 & -0.04 & -0.11 & -0.01 & 0.17 & 0.29 & 0.17 & 0.24 & 3.79 \\
\hline \multicolumn{12}{|c|}{ India } \\
\hline 12 & 0.64 & 0.15 & 0.77 & 0.90 & 0.77 & 1.00 & 0.94 & 0.68 & 0.93 & 0.46 & 1.00 \\
\hline 24 & -1.48 & -0.67 & -2.39 & $2.43^{b}$ & $2.41^{b}$ & $2.41^{b}$ & $2.41^{b}$ & 2.33 & 2.39 & 2.26 & 2.43 \\
\hline \multicolumn{12}{|c|}{ Philippines } \\
\hline 12 & 0.75 & -0.79 & 0.86 & -1.58 & -1.79 & -1.59 & -1.59 & -1.96 & -1.72 & -2.09 & 0.86 \\
\hline 24 & 1.60 & -1.32 & 1.52 & 1.28 & 1.42 & 1.27 & 1.16 & 0.99 & 1.06 & 0.91 & 1.60 \\
\hline \multicolumn{12}{|c|}{ Singapore } \\
\hline 12 & -0.12 & -0.81 & 0.05 & -1.01 & -0.95 & -1.01 & -1.28 & -1.11 & -1.41 & -1.27 & 0.05 \\
\hline 24 & 0.29 & 3.09 & 0.73 & -0.78 & -0.79 & -0.79 & -0.84 & -0.72 & -0.81 & -0.73 & 3.09 \\
\hline \multicolumn{12}{|c|}{ South Africa } \\
\hline 12 & -1.37 & 0.41 & -1.17 & $1.93^{b}$ & $1.95^{b}$ & $1.93^{b}$ & 1.62 & 1.36 & 1.68 & 1.37 & 1.95 \\
\hline 24 & -0.89 & 0.01 & -1.22 & 2.04 & 2.03 & 2.04 & 2.01 & 1.98 & 2.01 & 1.97 & 2.04 \\
\hline \multicolumn{12}{|c|}{ Taiwan } \\
\hline 12 & 1.25 & -0.92 & 1.51 & -1.56 & -1.58 & -1.59 & -1.56 & -1.58 & -1.67 & -1.70 & 1.51 \\
\hline 24 & -0.10 & -0.52 & 0.35 & -1.35 & -1.34 & -1.35 & -1.21 & -1.02 & -1.18 & -0.95 & 0.35 \\
\hline \multicolumn{12}{|c|}{ Thailand } \\
\hline 12 & 1.48 & -0.70 & 1.49 & -1.24 & -1.26 & -1.28 & -1.69 & -1.66 & -1.70 & -1.73 & 1.49 \\
\hline 24 & 1.53 & 0.17 & 2.04 & 0.24 & 0.27 & 0.30 & 0.14 & 0.18 & 0.13 & 0.06 & 2.04 \\
\hline
\end{tabular}


Table A6

\section{Long-Horizon Forecasts Based on Conditional Expectations of Factors}

The table presents the Diebold and Mariano (1995) and West (1996) MSFE ${ }_{i}^{k}-t$ statistics for currency $k$ based on the Newey and West (1987) estimator, which test the null hypothesis of equal mean squared forecast error (MSFE) between the random walk with drift benchmark (equation (2)) and the competing model in equation (i) $(i=3,4, \ldots, 15)$. The $l$-month ahead forecasts of exchange rate returns are from rolling regressions with a eight-year window using conditional expectations of risk factors. RC denotes $\max _{i=3,4, \ldots, 15} \mathrm{MSFE}_{i}^{k}-t$ statistic for reality check (best model) following Clark and McCracken (2012), which tests the joint null hypothesis of no predictive ability across all competing models. See also notes to Table A5.

\begin{tabular}{|c|c|c|c|c|c|c|c|c|c|c|c|c|c|c|}
\hline \multirow[b]{2}{*}{$l$} & \multicolumn{14}{|c|}{ Model } \\
\hline & 3 & 4 & 5 & 6 & 7 & 8 & 9 & 10 & 11 & 12 & 13 & 14 & 15 & $\mathrm{RC}$ \\
\hline \multicolumn{15}{|c|}{ Panel A: Developed Countries } \\
\hline \multicolumn{15}{|c|}{ Australia } \\
\hline 12 & 1.48 & 0.79 & 1.75 & -0.62 & 0.22 & -0.51 & 0.73 & 0.73 & 0.73 & 0.73 & 0.82 & 0.83 & 0.99 & 1.75 \\
\hline 24 & 3.03 & 2.04 & 3.07 & 2.51 & 2.23 & 2.70 & 0.94 & 0.94 & 0.94 & 1.03 & 0.99 & 0.92 & 0.90 & 3.07 \\
\hline \multicolumn{15}{|c|}{ Canada } \\
\hline 12 & 2.38 & 1.65 & $2.75^{b}$ & 1.05 & 0.89 & 1.20 & 2.04 & 2.04 & 2.04 & 2.02 & 1.87 & 1.74 & 1.52 & 2.75 \\
\hline 24 & 1.97 & 1.43 & 2.17 & 1.03 & 0.87 & 1.66 & 1.59 & 1.59 & 1.59 & 1.42 & 1.51 & 1.33 & 1.45 & 2.17 \\
\hline \multicolumn{15}{|c|}{ Germany $\backslash$ Euro Area } \\
\hline 12 & 2.59 & 2.13 & 2.63 & 2.27 & 1.86 & 2.33 & 1.86 & 1.86 & 1.86 & 1.80 & 1.59 & 1.75 & 1.60 & 2.63 \\
\hline 24 & 2.35 & 2.34 & 2.32 & 2.37 & 2.16 & 2.33 & 1.90 & 1.90 & 1.90 & 1.80 & 1.77 & 1.77 & 1.74 & 2.37 \\
\hline \multicolumn{15}{|c|}{ Japan } \\
\hline 12 & 0.74 & 1.97 & 0.99 & -0.66 & 1.45 & 0.65 & -0.19 & -0.19 & -0.19 & -0.11 & -0.62 & -0.38 & -0.62 & 1.97 \\
\hline 24 & 1.34 & 1.45 & 1.36 & 1.59 & 0.67 & 1.77 & -0.38 & -0.38 & -0.38 & -0.80 & -0.85 & -0.81 & -0.85 & 1.77 \\
\hline \multicolumn{15}{|c|}{ New Zealand } \\
\hline 12 & -2.33 & -2.44 & -1.32 & -1.85 & 0.32 & 0.19 & -0.71 & -0.71 & -0.71 & -0.28 & -0.20 & -0.04 & 0.10 & 0.32 \\
\hline 24 & 2.14 & -0.23 & 2.42 & 1.42 & -0.63 & 2.59 & -0.65 & -0.65 & -0.65 & -0.79 & -0.57 & -0.92 & -0.62 & 2.59 \\
\hline \multicolumn{15}{|c|}{ Sweden } \\
\hline 12 & 1.03 & 0.44 & 1.10 & 0.60 & 0.59 & 0.84 & -1.23 & -1.23 & -1.23 & -1.25 & -1.12 & -1.20 & -1.09 & 1.10 \\
\hline 24 & 1.18 & 1.02 & 1.22 & 1.18 & 0.27 & 1.14 & -0.40 & -0.40 & -0.40 & -0.23 & -0.54 & -0.18 & -0.37 & 1.22 \\
\hline \multicolumn{15}{|c|}{ Switzerland } \\
\hline 12 & 2.79 & 2.66 & 2.81 & 2.16 & 1.96 & 2.19 & 1.97 & 1.97 & 1.97 & 1.71 & 1.59 & 1.69 & 1.61 & 2.81 \\
\hline 24 & 2.59 & 2.39 & 2.50 & 2.53 & 2.19 & 2.50 & 1.84 & 1.84 & 1.84 & 1.76 & 1.74 & 1.76 & 1.77 & 2.59 \\
\hline \multicolumn{15}{|c|}{ United Kingdom } \\
\hline 12 & 1.42 & 0.93 & 1.63 & 0.71 & 1.40 & 1.12 & -1.80 & -1.80 & -1.80 & -1.79 & -1.23 & -1.76 & -1.09 & 1.63 \\
\hline 24 & -0.25 & 1.83 & 0.46 & -1.29 & 0.76 & -1.23 & -0.51 & -0.51 & -0.51 & -0.37 & -0.37 & -0.29 & -0.36 & 1.83 \\
\hline
\end{tabular}


Table A6 - Continued

\begin{tabular}{|c|c|c|c|c|c|c|c|c|c|c|c|c|c|c|}
\hline \multirow[b]{2}{*}{$l$} & \multicolumn{14}{|c|}{ Model } \\
\hline & 3 & 4 & 5 & 6 & 7 & 8 & 9 & 10 & 11 & 12 & 13 & 14 & 15 & $\mathrm{RC}$ \\
\hline \multicolumn{15}{|c|}{ Panel B: Developing Countries } \\
\hline \multicolumn{15}{|c|}{ Czech Republic } \\
\hline 12 & -2.32 & -2.79 & -2.09 & -2.60 & -3.19 & -2.32 & $1.83^{b}$ & $1.83^{b}$ & $1.83^{b}$ & $2.52^{a}$ & $3.06^{a}$ & $2.47^{a}$ & $3.11^{a}$ & $3.11^{b}$ \\
\hline 24 & 2.09 & 2.13 & 2.02 & 0.67 & 0.50 & 0.81 & 1.77 & 1.77 & 1.77 & 1.83 & 1.83 & 1.82 & 1.83 & 2.13 \\
\hline \multicolumn{15}{|c|}{ Hungary } \\
\hline 12 & $2.83^{a}$ & 2.31 & $2.85^{a}$ & $2.70^{b}$ & 1.83 & $3.18^{a}$ & 2.09 & 2.09 & 2.09 & 2.18 & 2.21 & 2.19 & 2.03 & 3.18 \\
\hline 24 & 2.10 & 2.34 & 1.95 & $3.96^{a}$ & $4.49^{a}$ & $3.42^{a}$ & -0.02 & -0.02 & -0.02 & 0.20 & 0.40 & 0.19 & 0.35 & $4.49^{b}$ \\
\hline \multicolumn{15}{|c|}{ India } \\
\hline 12 & 1.00 & 0.85 & 0.49 & $2.00^{a}$ & $2.04^{a}$ & $1.97^{a}$ & 1.11 & 1.11 & 1.11 & 1.54 & 1.53 & 1.57 & 1.49 & 2.04 \\
\hline 24 & -3.36 & -2.73 & -1.58 & -0.66 & -0.59 & 0.59 & $2.38^{a}$ & $2.38^{a}$ & $2.38^{a}$ & $2.31^{a}$ & $2.26^{a}$ & $2.31^{a}$ & $2.25^{b}$ & $2.38^{a}$ \\
\hline \multicolumn{15}{|c|}{ Philippines } \\
\hline 12 & 2.07 & 1.27 & 1.73 & 1.23 & -0.09 & 0.90 & -1.54 & -1.54 & -1.54 & -1.54 & -1.54 & -1.56 & -1.68 & 2.07 \\
\hline 24 & 0.99 & 1.09 & 1.44 & 1.78 & -0.50 & 1.82 & 1.28 & 1.28 & 1.28 & 1.20 & 0.90 & 1.11 & 0.81 & 1.78 \\
\hline \multicolumn{15}{|c|}{ Singapore } \\
\hline 12 & 1.39 & 1.00 & 1.41 & 1.22 & -1.40 & 0.94 & -1.00 & -1.00 & -1.00 & -1.32 & -1.20 & -1.50 & -1.47 & 1.41 \\
\hline 24 & -0.09 & 0.38 & 0.36 & 1.05 & 3.18 & 1.47 & -0.82 & -0.82 & -0.82 & -0.84 & -0.66 & -0.81 & -0.63 & 3.18 \\
\hline \multicolumn{15}{|c|}{ South Africa } \\
\hline 12 & 1.84 & 1.96 & 1.89 & $2.09^{b}$ & 0.71 & $2.04^{b}$ & $1.87^{b}$ & $1.87^{b}$ & $1.87^{b}$ & $1.85^{b}$ & -0.47 & 1.38 & -0.69 & 2.09 \\
\hline 24 & -1.34 & -1.37 & -1.32 & 1.45 & -0.15 & 1.40 & 1.96 & 1.96 & 1.96 & 1.69 & -0.16 & 1.52 & -0.23 & 1.96 \\
\hline \multicolumn{15}{|c|}{ Taiwan } \\
\hline 12 & 1.19 & 1.25 & 1.47 & 1.06 & 0.79 & 0.03 & -1.50 & -1.50 & -1.50 & -1.71 & -1.76 & -1.77 & -1.83 & 1.47 \\
\hline 24 & -1.57 & -0.92 & -1.59 & -0.43 & -0.62 & -0.82 & -1.44 & -1.44 & -1.44 & -1.32 & -1.24 & -1.36 & -1.30 & -0.43 \\
\hline \multicolumn{15}{|c|}{ Thailand } \\
\hline 12 & 1.17 & 1.24 & 1.45 & 1.43 & 0.35 & 1.52 & -1.14 & -1.14 & -1.14 & -1.66 & -1.69 & -1.75 & -1.83 & 1.52 \\
\hline 24 & $2.60^{b}$ & 2.09 & $2.89^{b}$ & $2.87^{b}$ & 1.06 & $2.22^{b}$ & 0.58 & 0.58 & 0.58 & 0.48 & 0.49 & 0.45 & 0.38 & 2.89 \\
\hline
\end{tabular}

